\section{Die GutsgärTnER VON REINHARDTSGRIMMA - ZWISCHEN ANSPRUCHSHALTUNG UND WIRKLICHKEIT}

Anja Gottschalk und Marie-Luis Unger

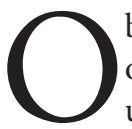
in der Vergangenheit, Gegenwart hardtsgrimmaer Gutsgärtner zu erzählen, ist oder Zukunft - ohne qualifizierte aufgrund der Aktenlage nicht möglich. und weitsichtige Gärtner wäre es Dennoch können anhand der überkommeschlecht um die Gartenkultur bestellt. Sach- nen Quellen recht plastische Eindrücke von verstand und Geschick waren und sind ei- den jeweiligen Lebens- und Arbeitswelten nerseits notwendig, um Parkanlagen ange- der über die Zeiten am Gut angestellten messen zu pflegen und zu erhalten. Ande- Gärtner vermittelt werden. Um die Gärtnerrerseits sind sie erforderlich, um florieren- persönlichkeiten umfassender auszuleuchden Zier- und Nutzgartenbau betreiben und ten, wurde versucht, ihre Lebenswege bis zur Sonderkulturen - in Reinhardtsgrimma wa- Bestallung in Reinhardtsgrimma, ihr Wirren es Ananas, Kamelien, Neuholländer und ken vor Ort und teilweise auch ihr späteres Palmfarne - kultivieren zu können. In der Schaffen nachzuvollziehen.

Auseinandersetzung mit historischen Gär- Anhand des vorliegenden Aktenmaterials ten ist es daher geboten, nicht nur die her- konnten insbesondere zwei Zeitphasen vorgebrachten Kulturleistungen, sondern nachvollzogen werden.

auch die dahinterstehenden Persönlichkei-

ten zu würdigen. Bislang gelten Biografien 1) Für die Zeit der Gutsherrschaft des Barons von Guts- und Schlossgärtnern jedoch wei- Friedrich Ludwig Ernst von Bülow (1738testgehend als Desiderat der Gartenfor- 1811) beziehungsweise der seiner Tochter schung - dieser Aufsatz versteht sich daher Friederike Juliane Christiane (1763-1832) zu als ein Beitrag, diese Forschungslücke zu Beginn des 19. Jahrhunderts liegt eine aufschließen. schlussreiche Gärtner-Bestallungsurkunde ${ }^{10}$ vor, die eine überaus bedeutsame Quelle für Im Zuge der vorgenommenen Untersu- die Gartenforschung zu Reinhardtsgrimma chung der Entwicklung des Gutsgartens in darstellt. Sie enthält Arbeitsanweisungen Reinhardtsgrimma wurde versucht, die einst und gewährt einen Einblick in die Lebensdort wirkenden Gärtner zu ermitteln - so führung des Gärtners Johann Friedrich Reukonnten sechs Gutsgärtner ${ }^{2}$ sowie eine Guts- ter (Lebensdaten unbekannt), aber auch in gärtnerin nachgewiesen werden: Johann die Gestaltung und Ausstattung des Gartens Friedrich Reuter (beschäftigt ab 1809) ${ }^{3}$, Wil- zu jener Zeit.

helm Ettrich (aktenkundig von 1907 bis 1913) ${ }^{4}$, Wilhelm Dobbrunz (aktenkundig 2) Aus der Herrschaftszeit von Friedrich von 1917 bis 1923) , Paul Raser (beschäftigt Hugo Maximilian Senfft von Pilsach (1854von 1924 bis 1927) ${ }^{6}$, Joseph Hinz (beschäftigt 1931) und seiner Ehefrau Alpheda Louisa von 1927 bis 1928) schäftigt von 1928 bis 1933, anschließend rial $^{11}$ überkommen, das die Biografien von Pacht der Schlossgärtnerei bis 1939) ${ }^{8}$ und drei (Raser, Hinz, Karliczek) zu dieser Zeit Christa Koppenfels (beschäftigt von 1939 bis angestellten Gutsgärtnern erhellt. Es zeigt 1945) ${ }^{9}$. Eine lückenlose Geschichte der Rein- sich, dass diese zumeist auf dem Gebiet des
Zier- und Nutzgartenbaus hochqualifiziert und in namhaften (Schloss-)Gärtnereien oder Parkanlagen ausgebildet worden waren. Immer wieder lässt sich zudem aus den Quellen lesen, dass die Senfft von Pilsachs anspruchsvolle Dienstherren waren, die ihren Gärtnern viel abverlangten und ein strenges Regiment führten. Erhalten sind zahlreiche Schriftwechsel zwischen Gutsherrschaft und Gärtnern, die zuweilen schwierige zwischenmenschliche Verhältnisse bekunden. Diese Umstände hatten verständlicherweise - kurze Bestallungszeiten und damit häufige Gärtnerwechsel zur Folge.

Für die darauf folgende Zeit der Gutsherrschaft des Försters Georg Conrad Ruschenbusch (1785-1866) und seines Schwiegersohns Hauptmann Ludwig Emil Aster (18331907) - während der ersten beiden Drittel des 19. Jahrhunderts - sind zwar keine Gutsgärtner namentlich überliefert, doch geben die Akten zumindest Auskunft über deren Arbeitswelt. Gärtnerische Aufgaben aus dem Betätigungsfeld des Ziergartenbaus, aber auch die Ertragssteigerung des Obstund Gemüsebaus der Schlossgärtnerei - als Stütze der Gutsökonomie - gewinnen nun an Gewicht. Ganz im Sinne dieser ökonomischen Fokussierung fordert Aster eine strenge Buchführung, wie nachfolgender Eintrag im Grundbuch aus seiner Feder veranschaulicht: »Es tritt eine neue, sorgfältig organisierte Buchführung ins Leben. $\aleph^{12}$

Im Flurbuch von 1875 vermerkt er zudem, welche Bücher vom Gärtner zu führen und wozu diese bestimmt sind.

»Gärtner führt:

1 Cassenbuch (zeigt nach Capiteln geordnet alle baren Einnahmen und Ausgaben der Gärtnerei)

1 Geldablieferungsbuch (zeigt alle von der Herrschaft erhaltenen Vorschüsse oder an dieselbe abgelieferten Gelder)

1 Bindereibuch, 1 Gemüsebuch, 1 Spargelbuch, 1 Baumbuch (zeigen die in jeder Reuters, 1809 (SächsHStAD, 10505 Grundherrschaft Branche verkauften Producte sowie die Reinhardtsgrimma, Nr. 179). dafür erzielten Geldbeträge)

1 Kaninchenbuch (zeigt den Zuwachs und Abgang im Kaninchenstall)

1 Instruction

1 Inventarverzeichnis. ${ }^{13}$

\section{Johann Friedrich Reuter (Tätigkeitszeit-} raum ab März 1809, Ende unbekannt)

Am 13. Januar 1809 unterzeichnete der Gärtner Johann Friedrich Reuter seine Bestallungsurkunde (Abb. 1) und trat am 1. März desselben Jahres seinen Dienst auf Reinhardtsgrimma an. ${ }^{14}$ Gutsherr zu jener Zeit war Baron Friedrich Ludwig Ernst von Büow. Aufgrund ihres hohen Aussagewerts für die Gartenforschung zu Reinhardtsgrimma soll der Inhalt der Bestallungsurkunde hier im Ganzen wiedergegeben werden:

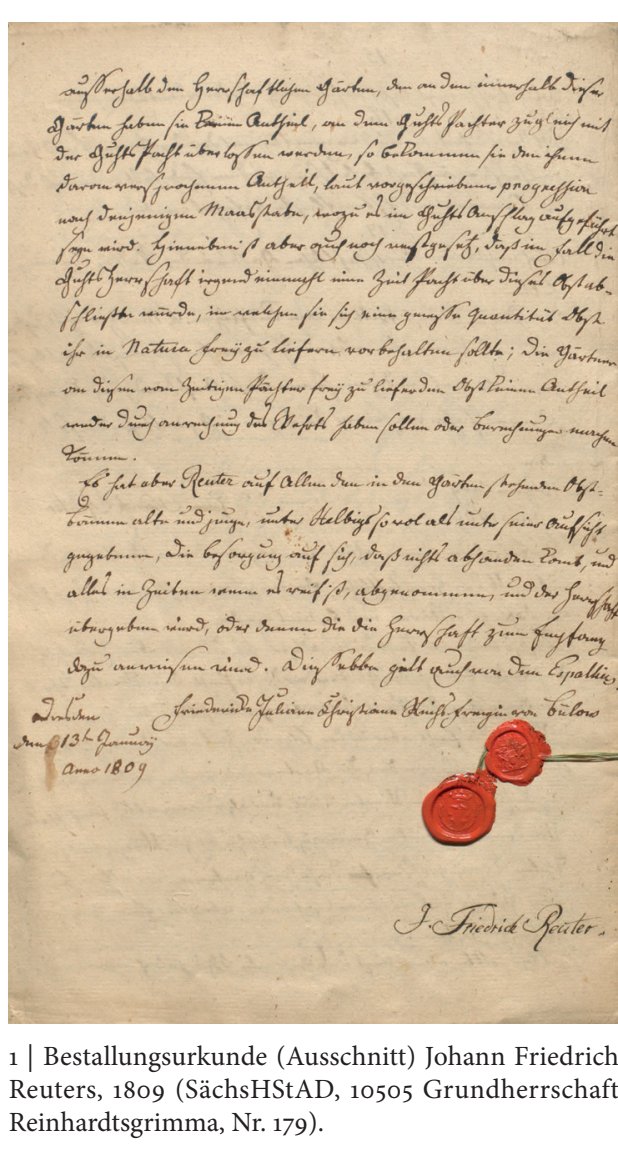


»Nachdem der Gärtner Johann Friedrich Reuter von der Gutsherrschaft des Ritter Guths Reinhartsgrimma, als Gärtner angenommen ist, so sind mit demselben folgende Bedingungen abgeschloßen worden:

1. Erhält der Gärtner Johann Friedrich Reuter an Jährlichen Gehalt, mit Einbegrif seines Gethränks und Brodt, welches Beides er sich selbst anschaffet, die Summe von Ein hundert und Zwantzig Reichsthaler Sächsisch Gelt, wovon ihm zum ersten Mahl nach Verlauf von Vier Monaten für Drey derselben, die folgende Zeit aber von Drey zu Drey Monate der vierteljährige Gehalt mit Dreißig Reichsthaler ausgezahlet wird, so daß er bey dieser jedesmahligen quartals Auszahlung bey der Guthsherrschaft für einen Monaht gut stehen hat.

2. Er erhält Mittags und Abends am herr schaftlichen Cammertisch oder wenn derselbe nicht statt fände für sich allein, dasjenige Essen welches für denselben zubereitet wird. Hiervon ist aber, wie schon vorher gesagt worden, Brodt und Gethränke ausgenommen, welches der Gärtner Reuter sich selbst halten muß. Über diesen erhält er auch noch jede Woche Drey Viertel Pfund Butter.

3. Wenn er in seiner Herrschaft Angelegenheiten und Dienst Verrichtungen über Land versant wird, so daß er wenigstens einen gantzen Tag von Hause abwesend ist, wohin aber nicht gerechnet werden kann, wenn er nach der Stadt zur Herrschaft kömt, wo er dann Essen und Thrinken erhalten wird, so bekömt er in jenen ersteren Fall Acht Groschen Auslösung.

\section{Dahingegen verspricht der Gärtner:}

1. Alles und Jedes in und außerhalb der Gärten, es sey im Küchen-GemüseBaum-oder Lust Garten, die entweder schon vorhanden sind, oder in der Folge noch angeleget werden sollen, so wie alle schon eingerichtete oder noch einzurich tenden Spatziergängen, willig, treu, fleißig und ordentlich vorzustehen und die dabey erforderliche Arbeit zu verrichten.

2. Alle Obstbäume, deren Anpflantzung Pfropfen und Innoculirung, Beschneidung, Anziehung aus dem Korn, mit einem Worte ihre gantze Cultur und Verpflegung in und außerhalb der Gärten, unter seiner Aufsicht zu nehmen, und die daran nöthige Arbeit vorstehen und be schaffen zu laßen, auch aller Orten wo es erforderlich seyn kann sowol des Nutzens als des Beyspiehls wegen, selbst mit Hand anzulegen.

3. Desgleichen verspricht der Gärtner die Ananas Cultur und das Treibehaus in besonderen Augenmerck zu haben, so vie Gewächse und Blumen anzuziehen wie nur immer möglich ist, die Ableger und den Saamen derselben für der Herrschaft wohl zu nutzen, so viel thunlich von ein und anderen, so wie auch von den Gemüsen Sämmereyen alljährlich zu sammeln und dahin zu sehen daß von solchen $\mathrm{Al}$ len nichts abhanden kommen, und die Herrschaft nicht genöthiget sey dessen viel für Geldt anzuschaffen.

4. In den Gewächshäusern darf er so wenig für sich als für andere, keine $\mathrm{Ge}$ wächse ziehen oder aufbewahren, es sey denn er habe von der Herrschaft die Erlaubniß dazu eingeholet.

5. Das Legen der Erdaepfeln im Garten und auf dem Felde, so wie das Ausnehmen derselben besorgt er auf das Pflichtmäßigste.

6. Es wird durchaus kein Verkauf aus denen Gärten, es habe Nahmen was es wolle so wie auch nicht von denen Früchten außer derselben nicht verstattet, und hat der Gärtner Reuter eine besonderen Aufmerksamkeit darauf zu richten daß
7. Weder von einer Herrschaft, Eigene, oder Fremde Diener, Dienstboten, Kinder oder fremde Leute, auch nur das Unbedeutendste entwendet, abgepflückt, an andern vergeben oder weggetragen werde. Wenn solches von jenen erstern geschehen würde, hat er solches so gleich zu melden, den letzteren es aber nicht zu gestatten und es ihnen wieder abzunehmen.

8. Er hat durchaus keine Kinder wenn sie nicht an der Hand geführet werden zu dulden, und wenn er eine Katze oder ein Raubthier in den Gärten oder Promenade bemerket, denen Jäger sogleich anzuzei gen, damit sie dieselben sofort tödten kommen. Auch keine Hunde, selbst nich die herrschaftlichen muß er im Garten dulden.

9. Da die Herrschaft die Vögel sehr lieb muß er ein wachsames Auge auf der Voliére haben, und das Nachstellen und Einfangen der Vögel im freien auch der Spuhr zu kommen suchen.

10. Bey Auffüllung des Eis Kellers im Winter hat der Gärtner die Aufsicht dabey zu führen, daß künftiges Eis gut hinein gebracht auch in der Grube wohl ein und zusammen geschlagen werde, und beim Anfahren des Eises die Fuhrleute, auf dem Fahrwegen bleiben und den Büschen und Sträuchern keinen Schaden zufügen.

11. Er hat für der Conservation des gantzen Inventarie an Zeug und Geschirre zu sorgen und des Abends von den Arbeitern abliefern und verschließen zu lassen.

12. Wenn das Obst von den Bäumen die Außerhalb der Gärten stehen, verpachtet wird, erhält er mit den andern Gärtner Helbig gemeinschaftlich ein Viertel der Pacht Summe, wogegen er sich aber auch die Conservation der Bäume auf alle Ar und die bestmöglichste Verpachtung der- selben angelegen seyn läßt, und Sorge trägt daß der Pächter, jedes Jahr seine, Laut Pacht Contract schuldige setzt, und laut solchen seine darin bedungene Pflicht gantz erfüllet.

13. Daß alle Grasung in den sowol unter ihm als unter Helbig stehenden Gärten, der Herrschaft zu Gute komme, läß er sich recht sehr angelegen seyn. So wie zu jeder Zeit Überall das was dem Herr schaftlichen Wiesn nützen kann, nich umkomn und nicht verschlagt werde; sondern von den Garten Arbeitern im Schloß oder dahin wo es angewiesen wird getragen werde. Auch muß er sich der Verbesserung der Rasen Plätze befleißigen.

14. In dem von ihm bewohnenden neuen Garten Hause behält sich die Herrschaft die beiden obersten Zimmer zu anderweitigen Bestimmung, so wie den Keller, und den Mitgebrauch der Küche, wie auch den gantzen Hüner Hoff bevor.

15. Holtz Ersparniß läßt er sich gantz außerordentlich angelegen seyn.

6. Mit der Einheitzung und namentlich mit der der Gewächs- und Treibe Häuse ist er äußerst behutsam, zu dem Ende hält er darauf, daß die Caminen und Essen fleißig gefeget werden.

17. Auch muß er den herrschaftlichen Garten in der Stadt in Ordnung halten.

Diesen Dienst tritt er am künftigen Martz dieses Jahres an. Er kann ihn nur ein Jahr vorher ehe derselbe entlassen seyn will aufkündigen, so wie diese Aufkündigung der ersten Dreyer Jahre von seiner Seite gar nicht statt finden soll.

Dresden

Am 13 January

Anno 1809

Johann Friedrich Reuter [Unterschrift des Gärtners; Anm. d. V. 
In Betref des denen Gärtnern zugestandenen Antheil an denen außerhalb den herrschaftlichen Gärten zu verpachtenden Obst, so ist solches dahin zu erklären und bestimmt worden;

Daß so lange die Pacht dieses Obstes bis, und nicht über, Zwantzig Reichsthaler beträgt, die Gärtner von dieser Pacht, den Vierten Theil von dem Betrag der Pacht Summe erhalten sollen.

Würde die Pacht aber in der Folge der Zeit über Zwanzig Reichsthaler hinansteigen, so würden die Gärtner wie vorhin, Laut dem im Königreich Sachsen seit 1769 von den ersten Zwanzig Reichsthalern geltenden Gesinderecht ${ }^{16}$ zählte Reuter als den Vierten Theil, und also namentlich Gärtner nicht zum landwirtschaftlichen, fünf Thaler von denen Zweiten Zwanzig, sondern zum häuslichen Gesinde. ${ }^{17}$ Obwohl und also bis zu Vierzig von jeden Thaler anders zu vermuten, wurde sein AufgabenZwey Groschen diese Zwey Gärtnern, von bereich den häuslichen Diensten zugeordnet allem hiernächst über Vierzig Thalern hi- und nicht dem Betrieb der eigentlichen naus gehenden aber nur Einen Groschen Landwirtschaft. ${ }^{18}$ Diese Zuordnung wirkte vom Thaler genügten.

Und sollte etwa nicht das gesamte Obst, jedoch immer nur das außerhalb den herrschaftlichen Gärten, den an den innerhalb dieser Gärten haben sie keinen Antheil, an den Guths Pächter zugleich mit der Guths Pacht überlassen werden, so bekommen sie den ihnen davon versprochenen Antheil, laut vorgeschriebener progression nach denjenigen Maasß tabe, wozu es im Guths Anschlag aufgeführet seyn wird. Hierueber ist aber auch noch festgesetzt, daß im Fall die Guthsherrschaft irgend einmahl eine Zeit Pacht über dieses Obst abschließen würde, in welchem sie sich eine gewiße Quantität Obst ihr in Natura frey zu liefern vorbehalten sollte; die Gärtner an diesen vom Zeitigen Pächter frey zu liefernden Obst keinen Antheil weder durch Anrechnung des Wehrts haben sollen oder Berechnun gen machen können.

Es hat aber Reuter auf Allen den in den Gärten stehenden Obst-Bäumen alte und junge, unter Helbigs sowol als unter sei- ner Aufsicht gegebenen, die Besorgung auf sich, daß nichts abhanden komt, und alles in Zeiten wenn es reif ist, abgenommen, und der Herrschaft übergeben wird, oder denen die die Herrschaft zum Empfang dazu anweisen wird. Daselbe gilt auch von dem Espallier.

\section{Dresden den 13ten January}

Anno 1809

Friedericke Juliane Christiane Reichsfreyin von Bülow [Unterschrift der Dienstherrin; Anm. d. V.] . $^{15}$ sich zum Beispiel auf die Kündigungsfrist aus. Üblich war die Gewährung eines Mozugestanden. Seine Kündigungsfrist betrug nicht nur ein ganzes Jahr, er durfte überhaupt erst nach drei vollen Beschäftigungsjahren kündigen

Reuter trat der Reinhardtsgrimmaer Hausgemeinschaft bei, als die Familie von Bülow ihren Besitz samt Schloss und Park systematisch erweiterte. Bereits 1801 hatte von Bügarten zu einem Landschaftsgarten umzugestalten (vgl Beitrag »Die Entwicklung der Gärten «). ${ }^{19}$ In diesem Zuge wurde 1805 auch ein neues Gärtnerhaus errichtet, in dem Reuter nun untergebracht war. ${ }^{20} \mathrm{Da}$ von Bülow viel Geld in diese Umgestaltung investierte, ist anzunehmen, dass der Gärtner angfristig gehalten werden sollte, um eine gewisse Pflegekontinuität zu gewährleisten und darüber hinaus, wie aus der Bestalungsurkunde (1. Instruktion) hervorgeht, den landschaftlichen Garten zu entwickeln. Nach der Umgestaltung musste beispielslow damit begonnen, den barocken Schloss- werden und bestehende Gehölze mussten Münchhausen (1643-1717) Fruchtreife erdurch Schnittmaßnahmen so entwickelt langten. ${ }^{21}$ Die Ananaskultivierung galt vor werden, dass sie das Bild des neuen Land- allem im 18. und 19. Jahrhundert als Statusschaftsgartens unterstützten.

Unter Reuters Obhut standen der Küchen-, der Gemüse-, der Baum- und der Lustgarten. Dies entsprach den üblichen Zuständigkeiten eines Gutsgärtners. Des Weiteren war Reuter in der Kultivierung der anspruchsvollen Ananas bewandert. Die Bestallungsurkunde (3. Instruktion) zeigt, dass die Fruchtbarmachung dieser besonderen Befähigung im Interesse der Herrschaft lag. symbol des Adels. ${ }^{22}$ Die ganzjährige Versorgung mit der süßen Frucht war dabei, aufgrund der Kostspieligkeit der besonderen Gewächshäuser, der Pflanzen selbst sowie der Anstellung speziell ausgebildeter Gärtner, ein Privileg wohlhabender Familien. Die Schwierigkeit in der Kultivierung lag (und liegt noch heute) insbesondere darin, die Temperatur im Boden und in der Luft des Gewächshauses nicht unter 30 Grad Celsius fallen zu lassen - auch im Winter, wofür Warmhäuser benötigt werden. ${ }^{23}$ Otto von Johann Christoph Volkamer (1644-1720) Münchhausen in Schwöbber besaß hierfür berichtet im zweiten Band seiner "Nürnber- gar ein Winter- und ein Sommer-Ananasgischen Hesperides « (1714) davon, dass die haus (Abb. 2). ${ }^{24}$ Diese waren so bekannt, Ananas in Deutschland zuerst im »Großbo- dass 1716 Zar Peter der Große (1672-1725) sischen Garten « in Leipzig und in Schwöb- um eine Besichtigung bat. ${ }^{25}$ Der Preußische ber bei Hameln im Garten des kurfürstlich- König Friedrich II. (1712-1786) beschäftigte hannoverschen Schatzmeisters Otto von wiederum einen Gärtner ausschließlich für

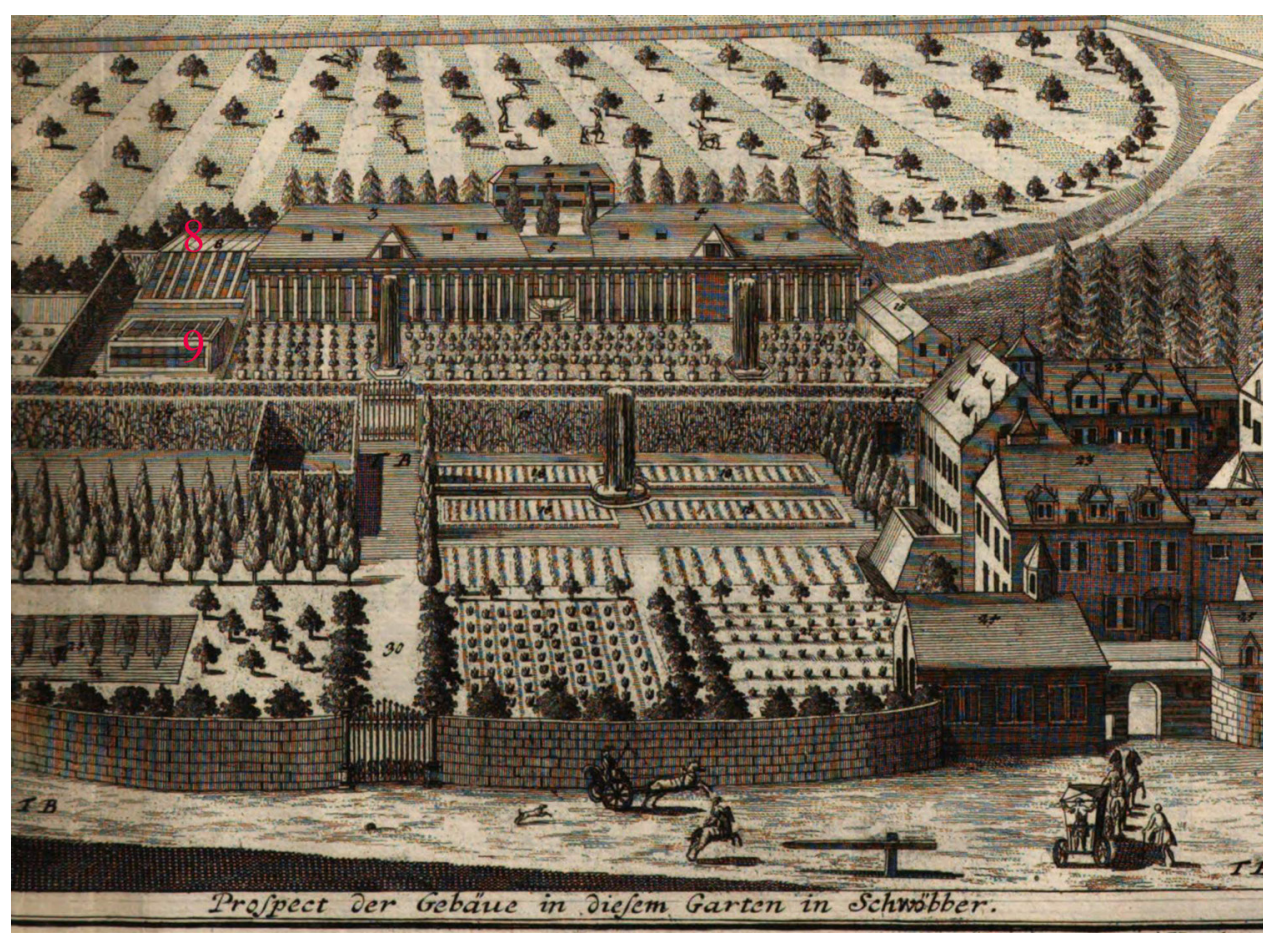

2 | Vogelschau von Schloss und Garten in Schwöbber, Kupferstich, das Winter-Ananashaus (8) und das SommerAnanashaus (9) Otto Münchhausens (aus Volkamer, Johann Christoph: Continuation der Nürnbergischen Hesperidum, Frankfurt am Main 1714, S. 58). 
die Ananaskultur. ${ }^{26}$ In den Schlossgärten Hand eines Erwachsenen betreten und von Sanssouci und Klein Glienicke wurde Raubtiere oder Katzen mussten sofort dem sie nur für den Hof angepflanzt. Hermann Jäger gemeldet werden. ${ }^{29}$

Fürst von Pückler-Muskau (1785-1871) ließ ebenfalls Ananas auf seinem Besitz anbauen Als eher unüblich für den Aufgabenbereich und verschenkte die kostbare Frucht an erle- eines Gutsgärtners kann Reuters Zuständigsene Gäste. ${ }^{27}$ Und das beschauliche Rein- keit für die Voliere, auf die er »ein wachsahardtsgrimma stand nicht zurück, auch hier mes Auge « haben sollte, erachtet werden..$^{3 \circ}$ wurde diese wertvolle exotische Frucht kul- Mit der ihm zudem zugewiesenen Aufgabe, tiviert und mit Reuter ein speziell ausgebil- der Beschaffung von Vögeln für die Voliere deter Gärtner beschäftigt.

Aber nicht nur die Versorgung der Schlossherrschaft mit Ananas fiel in Reuters Aufgabenspektrum. Auch frisches Obst und Ge- Laut Reuters Bestallungsurkunde wurde viel müse durften auf der Tafel der Familie von Wert auf die Pflege der Obstgehölze gelegt. Bülow nicht fehlen. Hierzu stand Reuter Sämtliche Obstgehölze in den Obstgärten dem Treibhaus vor, das es erlaubte, Früchte und an den Landstraßen standen unter seiauch außerhalb der Saison zu ernten sowie ner Aufsicht. Seine Aufgabe war es, die AnPflanzen für die Gärten vorzukultivieren. pflanzung, das Pfropfen und Innoculieren ${ }^{31}$ Zudem oblag ihm das Ziehen von Obstge- sowie das Beschneiden und Anziehen der hölzen an Spalieren (vgl. Bestallungsur- Bäume anzuleiten. Vorrangig koordinierte kunde, 3. Instruktion).

Dass der standesgemäße, kostspielige Le- "Nutzens und als das Beyspieles wegen " bensstil der Reinhardtsgrimmaer Herr- sollte er selbst zum Werkzeug greifen..$^{32}$ Reuschaften offenbar auch auf einem möglichst ter hatte sicherlich Gehilfen und Lehrlinge, kostensparenden Wirtschaften seitens des die ihm bei der Arbeit zur Hand gingen. Personals fußte, zeigt sich, wenn Reuter Auch wurden bei größeren, einmaligen Aufdazu angehalten wird,

"von den Gemüsen Sämmereyen alljährlich zu sammeln, und dahin zu sehen daß von solchem Allen nichts abhanden kommen, und die Herrschaft nicht genöthiget sey dessen viel für Geldt anzuschaffen $\aleph^{28}$.

Wohl aus demselben Grund sollte er auch mit dem Holz zur Beheizung der Gewächshäuser sparsam umgehen. Von ebenjener Sparsamkeit - aber auch von Strenge - zeugen weitere Regelungen: Der Anbau für den Eigenbedarf sowie der Verkauf von Gartengütern waren dem Gärtner untersagt. Die produzierten Nahrungsmittel waren allein für die Versorgung der Herrschaft bestimmt. Jegliche Entwendung sollte angezeigt und das "Diebesgut « möglichst konfisziert werden. Kinder durften den Garten nur an der standen (13. Instruktion), um welche Gärten es sich hierbei handelte, bleibt unbenannt. Zudem wurden Reuter und ihm jeweils ein Viertel der genannten Pachtsumme, sofern diese 20 Sächsische Reichstaler nicht überstieg, zu gleichen Teilen zugesprochen.

Für seine Arbeit erhielt Reuter jährlich 120 Sächsische Reichstaler. ${ }^{34}$ Im Vergleich dazu konnte ein Hofgärtner am preußischen Hof je nach Alter und Erfahrung mit einem Gehalt von 400 bis 700 Talern pro Jahr rechnen. ${ }^{35}$ Von Hofgärtnern wurden allerdings gärtnerische Höchstleistungen und überdies gartenplanerische Befähigungen erwartet. So hatten sie zum Einen den Hof ganzjährig und in großen Mengen mit frischem Obst und Gemüse zu versorgen - ab der Mitte des 18. Jahrhunderts wurden zudem südländische Früchte, wie die bereits erwähnte Ananas und Süßorangen, das ganze Jahr über auf den fürstlichen Tafeln erwartet. ${ }^{36}$ Zum Anderen waren sie neben dem gärtnerischen Pflanzenbau auch mit dem Entwerfen von Gärten und Gartenbereichen betraut. Außerdem waren sie in der Verbreitung neuer Arten und Sorten federführend, da sich die Fürsten gern mit botanischen Besonderheiten übertrumpften. ${ }^{37}$

Als Gutsgärtner stand Reuter im Rang unter den Hofgärtnern, über besondere Qualifikationen ist, abgesehen von seinen Fähigkeiten im Ananasanbau, nichts bekannt. Auch über sein Alter und seine Erfahrungen können keine Aussagen getroffen werden. Sein Gehalt, das ihm im damals gebräuchlichen Rhythmus von drei Monaten ausgezahlt wurde, kann höchstwahrscheinlich als üblich angesehen werden. Die wöchentlichen dreiviertel Pfund Butter, die er zudem erhielt, zeugen von einem Mischlohn aus Geld und Naturaliengaben, wie er Anfang des 19. Jahrhunderts durchaus typisch war. Die genaue »Zusammensetzung« dieser Entlohnung wurde in den jeweiligen Dienstverträgen festgehalten. ${ }^{38} \mathrm{Oft}$ wurden den Dienstboten zwei Pfund Brot pro Tag zugesprochen, das zu den Mahlzeiten im Esszimmer für das Gesinde verzehrt wurde. ${ }^{39}$ Hier nahm auch Reuter mittags und abends Platz. Jedoch wurde ihm keine Brotration gereicht. Um diese musste er sich, ebenso wie um $\mathrm{Ge}$ tränke, selbst kümmern. ${ }^{40}$ Diese Lösung empfahl beispielsweise Christian Friedrich Germershausen (1725-1810) in seinem Hausmutterbüchern ${ }^{41}$, wenn die Haushaltung von geringerer Größe war oder die Herrschaften beziehungsweise die Hausmutter befürchteten, dass das Gesinde die zugeteilten Lebensmittel an Dritte weitergab. ${ }^{42}$ Im Kreise der Dienerschaft war Reuter möglicherweise ein sehr bereichernder Gesprächspartner. Seine Fähigkeiten als Gärtner lassen auf eine gewisse Bildung schließen, die über das Lesen und Schreiben hinausging. Es könnte durchaus sein, dass Reuter auch Fremdsprachenkenntnisse besaß, denn die damalige wissenschaftliche Gartenlektüre wurde hauptsächlich in Latein (Pflanzennamen und -beschreibungen), Französisch (Obstarten, Blumensorten) und Italienisch (Zitrusbäumchen) verfasst. Auch war es gemäß den alten Handwerksbräuchen für Gärtner üblich, nach ihrer dreijährigen Lehrzeit auf Reisen zu gehen. Meist arbeiteten sie als Gesellen für ein Jahr in einem Garten, um dort - bei Entlohnung in Form von Kost und Logis - Erfahrungen im gesamten Jahreszyklus zu sammeln..$^{43} \mathrm{Im}$ Gepäck hatten die Gesellen auf ihren Reisen meist nicht viel, aber immer ihren Geburtsbrief, den Lehrbrief und einen Nachweis über die letzte Beschäftigung. Von Gärtner Reuter liegt weder ein Lehrbrief vor, noch besteht Kenntnis über seine letzte Beschäftigung vor seiner Bestallung in Reinhardtsgrimma. ${ }^{44}$ Wo er sich sein Wissen aneignen konnte, wo er herkam und was die Zukunft für ihn bereithielt, ist - ebenso wie das Datum seines Dienstaustritts - unbekannt.

Paul Raser (Tätigkeitszeitraum Oktober 1924 bis Februar 1927)

Mit einem Schreiben vom 11. August 1924 aus Dittersbach, Kreis Sagan, Provinz Niederschlesien (heute Dzietrzychowice, po- 
warb sich Paul Raser (geboren am 14. Sep- Uciechów, powiat dzierżoniowski, wojetember 1880 im oberschlesischen Zabrze, wództwo dolnośląskie) im Geschäft des Kreis Zabrze, Provinz Schlesien (heute Zab- Gärtners Hans Bodendorf beschäftigt. Von rze, powiat Zabrze, województwo śląskie)) - da aus bewarb er sich auf eine Stelle als offenbar in Reaktion auf ein Gesuch - bei Schlossgärtner auf dem Rittergut Tannhauder damaligen Gutsherrschaft, den Senfft sen, Kreis Waldenburg, Provinz Schlesien von Pilsachs (Abb. 3):

"An die Rittergutsverwaltung Reinhardtsgrimma: Das Landwirtschaftliche Geschäft Paul Kramer Breslau teilte mir mit, daß die dortige Wohllöbliche Ritter gutsverw[altung] einen verh[eirateten] Gärtner suchte und wurde mir anheim gestellt mich um die Stellung zu bewerben. Bin $43 \mathrm{~J}$ [ahre] alt, verh[eiratet], gute[r] Gesinnung, firm in allen Zweigen meines Berufes erfahren fleißig selbsttätig nüchtern ehrlich und äußerst zuverlässig. Bin firm in der Bedienung der Centralheizung. Gehaltsansprüche mach ich nicht da sich dies nach den dortigen Verhältnissen richtet jedoch möchte ich bitten, daß mir Viehhaltung gestattet wäre. Ich bin in Bezug auf Lohnforderung sehr bescheiden. Antritt könnte wie gewünscht erfolgen. Ich habe noch drei Kinder zu Haus wovon 1 Mädchen Ostern die Schule verläßt und so jedes Jahr. Anbei meine Zeugnisabschriften nebst einer Empfehlung meines jetzigen Herrn Chefs und Bild. Einen gütigen Bescheid entgegen sehend. Zeichnet mit größter Hochachtung P. Raser Schloßgärtner Dittersbach, Kreis Sagan. Ich bin geborener Schlesier ${ }^{45}$

Anhand von Zeugnisabschriften, die Raser seiner Bewerbung bei Senfft von Pilsachs beilegte, lässt sich sein Werdegang rekonstruieren. Sie stellen somit überaus bedeutsame Quellen dar und bekunden, dass Raser ein schaffenskräftiger Gärtner war, der mit viel Fleiß und zur Zufriedenheit seiner Dienstherren agierte und insbesondere gute Ernteerträge im Gemüseanbau erzielte.

Als Landschaftsgärtner war Raser für sieben Jahre - von 1905 bis 1912 - in Bertholsdorf Kreis Reichenbach, Provinz Schlesien (heute (heute Jedlina-Zdrój, powiat wałbrzyski, województwo dolnośląskie) (Abb. 4) des Gutsbesitzers Gustav Adolf Böhm (18641933), wo er vom 1. April 1912 bis zum 1. Jul 1913 in Stellung war. Böhm berichtet in einem im Juni 1913 verfassten Zeugnis:

»Er tat alle ihm zukommenden Arbeiten. Gemüsegarten, Glashaus, Park in Ordnung halten, auf das Beste erledigt. War arbeitsam und willig. Sein Abgang erfolgte auf eigenen Wunsch. Raser war, wenn es nötig an Leuten fehlte, auch in der Heuernte tätig, kurz, er scheute sich vor keiner Arbeit. « ${ }^{46}$

Die nächste Station seiner beruflichen Laufbahn brachte Raser nach Mellendorf, Kreis Reichenbach, Provinz Schlesien (Młynica, powiat dzierżoniowski, województwo dolnośląskie) im Eulengebirge, wo er von 1914 bis 1920 bedienstet war. Am 9. Mai 1920 verfasste Hermine Prinzessin von Schönaich-Carolath (1887-1947; geborene Reuß, ältere Linie), die 1922 die zweite Ehefrau des deutschen Kaisers und preußischen Königs Wilhelm II. (1859-1941) wurde, ein Empfehungsschreiben für Raser. Sie war in erster Ehe mit Prinz Johann Georg zu SchönaichCarolath (1873-1920) verheiratet, mit dem sie auf Saabor, Kreis Grünberg, Provinz Schlesien (heute Zabór, powiat zielonogórski, województwo lubuskie) lebte und zu dessen Besitzungen auch das Gut in Mellendorf gehörte. Sie empfiehlt Raser mit lobenden Worten:

»Der Schlossgärtner Paul Raser war vom 1. April 1914 bis April 1920 als solcher in Mellendorf, er hat dort seine Pflicht in jeder Weise erfüllt, er ist ein sehr gewissenhafter, tüchtiger und erfahrener Gärtner fleissig, ehrlich, nüchtern, anständiger
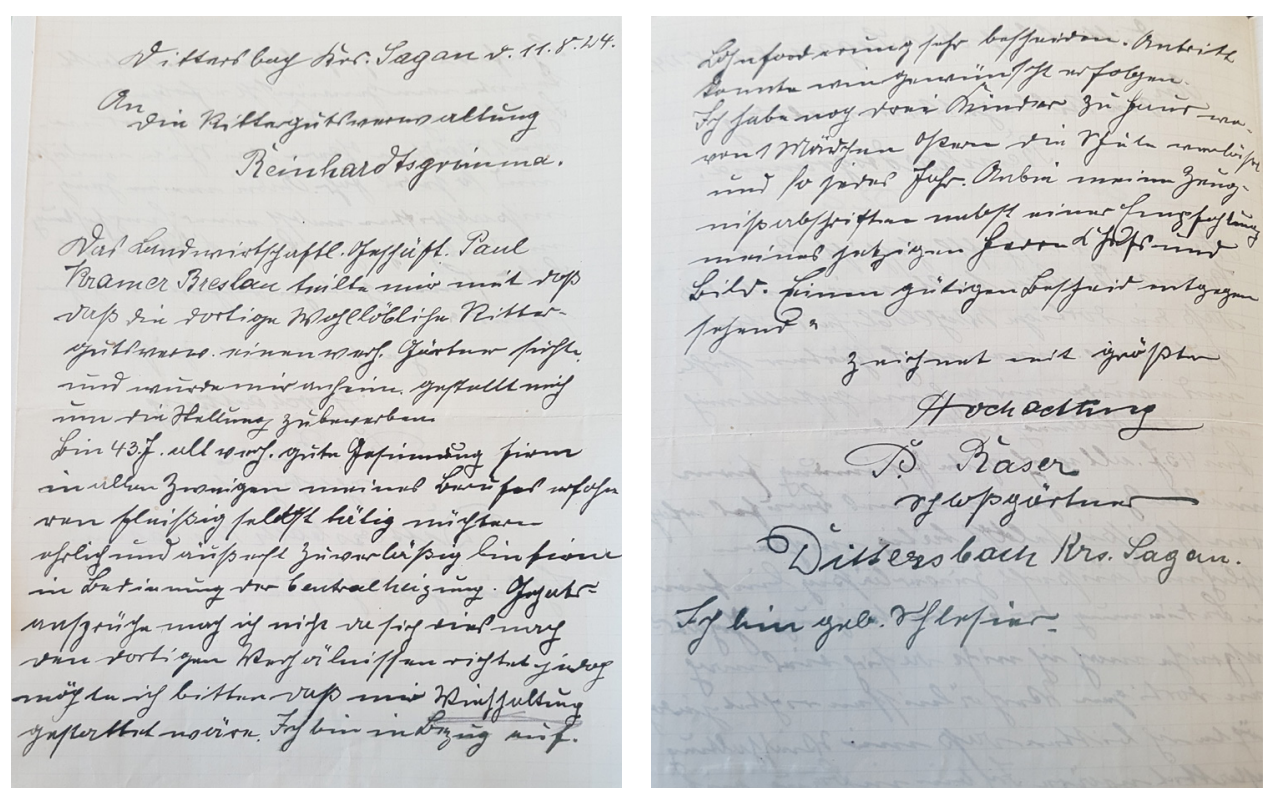

Bewerbungsschreiben Paul Rasers an die Familie Senfft von Pilsach vom 11. August 1924 (SächsHStA, 10505, Nr. 330, Personalangelegenheiten des Gärtners Paul Raser in Reinhardtsgrimma 1927).

Gesinnung. Den Krieg über war er fort, Rasers Dienstherr, Arnold (Arno) von und besorgte währenddess seine Frau den Oheimb (1882-1958), war der Sohn FriedGarten. [...] Ich empfehle ihn wärmstens. rich (Fritz) von Oheimbs (1850-1928), der Er würde auch grossen Ansprüchen durchaus entsprechen."

Zudem berichtet die Prinzessin von den Gründen des Fortgangs Rasers:

»Raser verliess uns, da meine Schwiegermutter [Wanda Adelheid Bianca Clementine Cäcilie von Schönaich-Carolath, 1849-1925, gestorben auf Mellendorf] Mellendorf mit Garten mietete und eine Gärtnerin nehmen wollte, wir hätten Raser sonst bestimmt behalten. « ${ }^{47}$

Nachdem Raser nach sechs Jahren Dienst Mellendorf verlassen hatte, führte ihn sein Weg in das von der Familie von Oheimb betriebene Arboretum Woislowitz, Kreis Nimptsch, Provinz Schlesien (heute Wojsławice/Niemcza, powiat dzierżoniowski, województwo dolnośląskie). Die Anstellung bei von Oheimb ist wohl die interessanteste der überlieferten Stellungen. (Fritz) von Oheimbs (1850-1928), der Woislowitz sowie als einer der Gründungsschen Dendrologischen Gesellschaft in die Geschichte einging. Nachdem er 1880 den verwahrlosten Gutspark in Woislowitz gekauft hatte, widmete er sich der Anlage eines Rhododendrongartens, dem zeitlebens sein besonderes Augenmerk galt. Aber auch exotische Ahorne und Päonien gehörten zu seinen botanischen Interessen. Weithin bekannt wurde der Park aufgrund seiner botanischen und dendrologischen Raritäten, heute ist er ein Standort des Botanischen Gartens der Universität Breslau. Bekannt ist auch Fritz von Oheimbs Werk »Gartenglück von heute", das er 1926 im Verlag der Gartenschönheit (Berlin) veröffentlichte. $\mathrm{Ab}$ 1921 lenkte sein Sohn Arnold die Geschicke der Gutswirtschaft, die Aufsicht uber die botanischen Anlagen hatte jedoch weiterhin sein Vater inne. ${ }^{48}$ väter der 1892 ins Leben gerufenen Deut- 


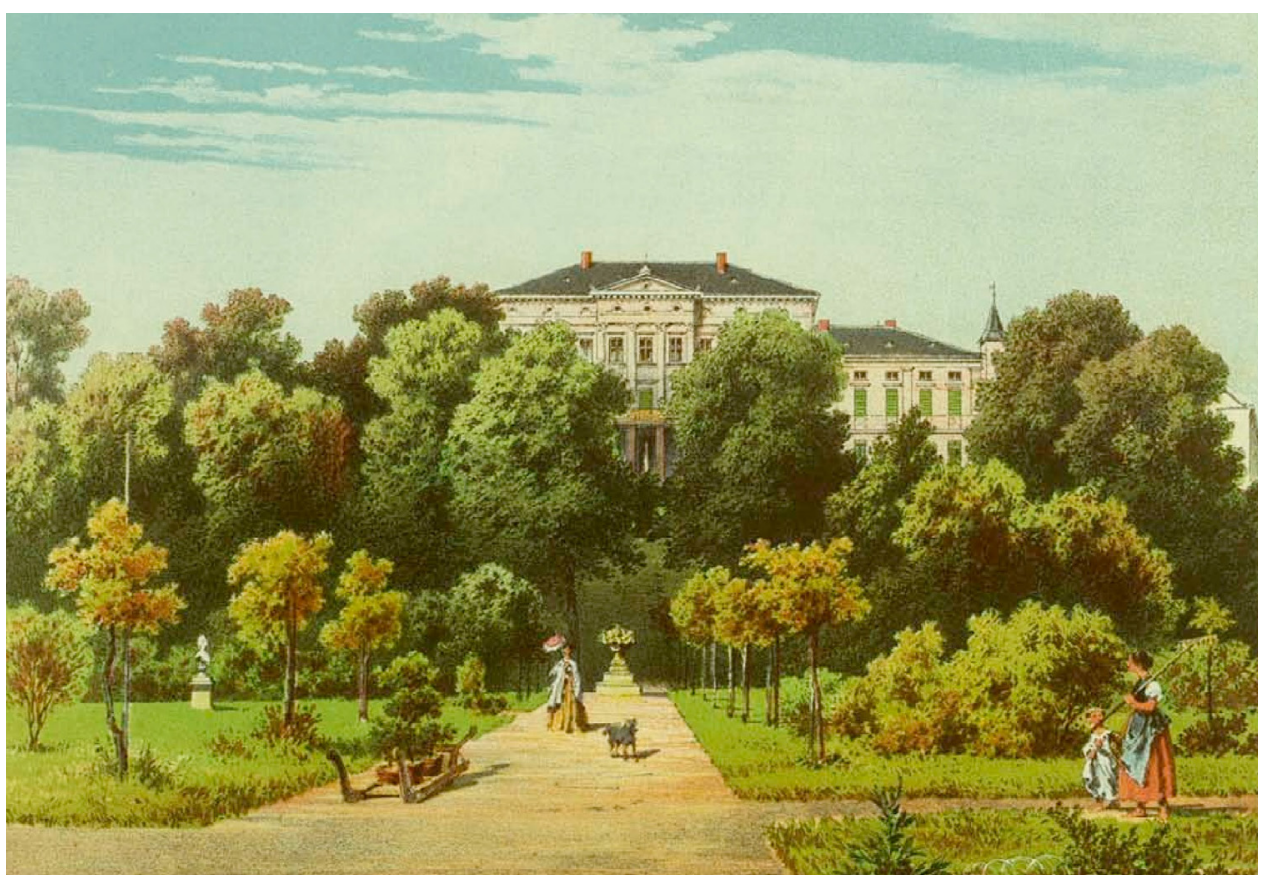

| Ansicht von Schloss und Garten Tannhausen, Farblithographie von Theodor Albert nach einer Zeichnung von Theodor Blätterbauer (aus Duncker, Alexander: Die ländlichen Wohnsitze, Schlösser und Residenzen der ritterschaftlichen Grundbesitzer in der preußischen Monarchie nebst den Königlichen Familien-, Haus-Fideicommissund Schatullgütern, Band 11, Berlin 1869/70, S. 95)

Raser blieb für zwei Jahre, vom 1. April 1920 scheinlich im Zuge oder Nachgang des Ersbis zum 1. Oktober 1922, in den Oheimb- ten Weltkriegs), die offenbar eine psychische schen Anlagen beschäftigt. Oheimb zeigte Erkrankung (»Nervosität«) nach sich zog, sich in Rasers Zeugnis sichtlich betroffen welche sich allerdings gebessert habe. Auüber dessen Fortgang und lobte ihn in den Berdem wird die »Kränklichkeit seiner höchsten Tönen: »Ich habe noch nie einen Frau« angesprochen, durch die Raser »viel fleissigeren oder auch nur ebenso fleissigen häusliche Arbeiten allein überlassen « waren Gärtner gehabt. «49 Zudem wird Raser als - allerdings verbindet Oheimb dies mit der »vortrefflicher, ehrenhafter Charakter" und Aussicht, dass dieser Zustand »hoffentlich "sehr gelehrig" - so habe er sich die Stau- durch die soeben überstandene Operation denzucht schnell angeeignet - beschrieben. endgültig beseitigt ist «.

Interessant in Bezug auf seine spätere An-

stellung in Reinhardtsgrimma, gerade vor Die letzte Bestallung vor seiner Tätigkeit in dem Hintergrund der Sparsamkeit der Senfft Reinhardtsgrimma hatte Raser bei Dr. Friedvon Pilsachs in gärtnerischen und landwirt- rich Heimann-Trosien (Lebensdaten unbeschaftlichen Angelegenheiten, erscheint vor kannt) in Dittersbach, Kreis Sagan, Provinz allem die Einschätzung Rasers als »kluger Niederschlesien (heute Dzietrzychowice, Rechner, guter Verkäufer«. Aus dem Schrei- powiat żagański, województwo lubuskie) ben Oheimbs gehen überdies einige biogra- inne. Auch hier wurde ihm ein sehr gutes fische Details hervor, die von einem nicht Arbeitszeugnis ausgestellt, das zugleich Inimmer leichten Schicksal künden. So er- formationen zu seinen Tätigkeitsfeldern wähnt er eine längere Gefangenschaft (wahr- und Fähigkeiten liefert. So hatte er ein
»Warm- und Kalthaus, Frühbeete und circa 25 Morgen Nutz- und Parkland « zu versorgen, wobei insbesondere die Kenntnisse zur Bewirtschaftung von Warm- und Kalthaus, die auch in Reinhardtsgrimma existierten, für Senfft von Pilsachs interessant gewesen sein dürften. Raser wird darüber hinaus als bewandert »auf allen Gebieten der Blumenzucht « beschrieben und es werden demzufolge seine besonderen Fähigkeiten in der Gemüsekultivierung hervorgehoben:

»Am besten standen seine großen Gemüsekulturen. Man kann Raser hierfür als Spezialist bezeichnen, da er gerade bei Gemüsen, soweit es bei den einzelnen Verhältnissen möglich war, Rekordernten erzielt hat. $\aleph^{50}$

Bei der Bewältigung des Aufgabenspektrums schien ihm der bessere Gesundheitszustand seiner Frau zugute zu kommen, denn sie »half stets aus, sowohl im Garten als im Haushalt«. Als Grund für Rasers Entlassung gibt Heimann-Trosien wirtschaftliche Ursachen an, die ihn zwingen, "von zukünftiger Einstellung und Beschäftigung eines Gärtners absehen « zu müssen. ${ }^{5}$

Von Rasers Wirken auf Reinhardtsgrimm ist nicht viel überliefert. Aus einem Schreiben Senfft von Pilsachs geht das genaue $\mathrm{Da}$ tum seines Beschäftigungsbeginns (1. Oktober 1924) hervor. Zudem werden darin auch einige Betätigungsfelder benannt, so »Verkauf und Erwerb von Produkten ", »Gemüsegärtnerei und Parkpflege«, »Pflege des Obstes auf den Landstraßen « und die Versorgung der »Centralheizung im Schloß«, die Raser wiederum als recht vielseitig ausweisen. ${ }^{52}$

Neben diesem Schreiben liefert lediglich eine Akte mit Gärtnereirechnungen von 1926-1927 $7^{53}$, deren Bestellungen auf Raser zurückgehen müssen, Anhaltspunkte zu dessen Handeln in Reinhardtsgrimma. Anhand dieser Rechnungen kann ausgesagt werden, dass sich Raser wohl auch umsichtig um die Instandhaltung der Gebäude be- mühte, da dort Bestellungen von baulichem Zubehör für die Gärtnerei oder von »hell blaugrauer Gärtnerölfarbe« - vermutlich zum Streichen der Frühbeetfensterrahmen aufgeführt werden. Interessant sind auch eine Bestellung bei der Baumschule Franz Haas, Hofstetten-Gemünden am Main (Bayern), vom 15. April 1926, bei der Raser »100 Stk Apfel-Hochstämme in Sorten « ${ }^{54}$ anforderte, sowie ein Akteneintrag, dass Raser 1926 bei der Rosen- und Obstbaumschule von Heinrich Heckmann in DresdenStetzsch

»10 Clematis, 1 Pfirsich, 5 Stachelbeer sträucher, 5 Johannisbeeren, 15 Rosen Hochstämme, 31 Rosen Hochstämme, 5 Schlingrosen, 25 Rosen niedrige Strauchrosen $\ll^{55}$

anschaffen ließ. Möglicherweise wurden die bestellten Rosen zur Bepflanzung der Schmuckbeete vor der Gartenseite des Schlosses, die um 1910 unter den Senfft von Pilsachs realisiert wurden, genutzt.

1927 wurde Raser aufgrund von wirtschaftlichen Nöten seitens der Gutsherrschaft gekündigt, wie aus seinem Arbeitszeugnis hervorgeht:

"Ich entlasse ihn weil die jetzt herrsch[enden] Wirtschaftsverhält[nisse] mich veranlassen andere Einrichtungen $\mathrm{zu}$ treffen und bedaure, mich von einem Mann vorzüglichen, zuverlässigen Charakters und anständiger Gesinnung trennen zu müssen. Ich möchte seinen Fleiß, Gewissenhaftigkeit, auch in der Rechnungsführung und beim Verkauf und Erwerb von Produkten hervorheben. Er ist auf allen Gebieten der Gemüsegärtnerei und Parkpflege bewandert, hatte auch die Pflege des Obstes auf den Landstraßen zu besorgen und die Centralheizung im Schloß. Seine Frau half im Gärtnereibetrieb. Meine besten Wünsche begleiten das Ehepaar auf ihrem ferneren Lebensweg. $11^{56}$ 
Es sind einige Briefdokumente erhalten, die Rasers Leben nach dem Weggang aus Reinhardtsgrimma erhellen. Offensichtlich hatte sich Raser auf eine Gutsgärtnerstelle beworben, die über den bekannten Gartenarchitekten und Präsidenten der Deutschen Gartenbaugesellschaft Ludwig Lesser (18691957) vermittelt wurde. Um ein umfassendes Bild von dem Gärtner zu erhalten, holte Lesser Erkundigungen über Raser bei General
major Maximilian Senfft von Pilsach ein:

»Berlin-Steglitz, den 12. Nov. 1927,

Sehr geehrter Herr! Für einen meiner Auftraggeber, der in der Nähe von Berlin ein kleines Gütchen als Wochenende gekauft hat, suche ich einen vollständig gewissenhaften und zuverlässigen Gärtner, der auch von der Landwirtschaft etwas versteht und eine Frau hat, die ebenso zuverlässig und fleißig ist und Erfahrungen besonders in der Milchwirtschaft und in der Geflügelzucht besitzt. Unter den vielen Bewerbern, die sich auf ein diesbezügliches Inserat hin gemeldet haben, befindet sich auch ein Gärtner Paul Raser, z. Zt. Kutschlau bei Schwiebus [Kutschlau, Kreis Züllichau-Schwiebus, Provinz Brandenburg (heute Chociule, powiat świebodziński, województwo lubuskie)]. Ich habe mir dieses Gärtnerehepaar kommen lassen, um dasselbe erst einmal kennen zu lernen, und muß sagen, daß beide einen sehr guten Eindruck gemacht haben. Frau Raser frug ich inbezug darauf, ob die früher bei ihr vorgenommene Operation irgend welche Folgen habe, worauf sie mir erwiderte, daß sie jetzt vollkommen gesund sei.

Da der Gärtner Raser lt. einer seinem Bewerbungsschreiben beigelegten Zeugnisabschrift vom 1. Oktober 1924 bis 9. Februar 1927 bei Ihnen, sehr geehrter Herr beschäftigt war, so würden Sie mich und meinen Auftraggeber zu großem Danke verpflichten, wenn Sie mir gütigst möglichst umgehend Näheres über den Charakter und die Eigenschaften des Ehepaares Raser mitteilen würden. Sie haben dem Gärtner Raser ja so ein vorzügliches Zeugnis gegeben, aber trotzdem gestatte ich mir noch ein Mal an Sie um eine Auskunft hierdurch zu bitten. ${ }^{57}$

In seinem Antwortschreiben an Lesser äuBert Senfft von Pilsach recht deutlich seine Unzufriedenheit hinsichtlich der Arbeit Rasers sowie seinen Unmut darüber, ihn mit einem guten Zeugnis bedacht zu haben:

»Sehr geehrter Herr, in meinem lebhaften Bedauern muß ich davon abraten dem Gärtner Raser als solchen in Ihren Dienst zu nehmen. Nach seinem Weggang von hier am 1.4.1927 sind sehr bald recht unangenehme Entdeckungen gemacht worden. Er hat sich allerhand Unannehmlichkeiten und Nachlässigkeiten zu Schulden kommen lassen. [...] Daß ich es sehr bedaure ihm ein so gutes Zeugnis gegeben zu haben. $\aleph^{58}$

In dieser Zeit erreichte zudem ein Schreiben von Ernst Laux ${ }^{59}$ auf dem Rittergut Großjena (heute Ortsteil von Naumburg an der Saale) mit demselben Anliegen die Senfft von Pilsachs - offenbar hatte sich Raser auch dort auf eine Gärtnerstelle beworben:

»Herr General würden mich zu großen Dank verpflichten, wenn Sie mir über den bei Ihnen bis vor einem halben Jahr beschäftigt gewesenen Gärtner Paul Raser eine möglichst ausführliche Auskunft geben würden. Mir fällt auf, daß dem Raser immer gekündigt wurde, weil der Betrieb umgestellt wurde, und dies nach kurzer Anwesenheit des Raser in den Betrieben. Ist der Mann durch Beanspruchung vieler Hilfskräfte zu teuer? [...] Will Raser mehr den Obergärtner spielen, hilft ihm seine Frau mindestens $4-5$ Tage in der Woche mit? Was hat er für Familie? Hat er auch Erfahrung in Blumentreiberei und Gewächshauskultur? Ist er flott in der Arbeit und nie müßig, und die Frau nicht schwatzhaft? ${ }^{60}$
Senfft von Pilsachs Antwort auf die Anfrage ist nicht überliefert, dafür aber ein an ihn gerichteter Brief Rasers vom 21. November 1927, der Aufschluss darüber gibt, dass der Major auch hier nicht zu Gunsten des Gärtners agierte und die Gutsherren grundsätzlich recht rigide mit ihm umgingen. Zudem werden aus diesem Brief die Vorwürfe der Senfft von Pilsachs gegenüber Raser ersichtlich und es eröffnen sich interessante Einblicke in das soziale Miteinander der auf dem Gut Beschäftigten, weshalb der Brief hier in seiner gesamten Länge wiedergegeben werden soll:

»Hochwohlgeborener Herr General!

Leider bin ich gezwungen[,] mich heut brieflich an Herrn General zu wenden, mit der Bitte[,] mir in meinem Fortkommen nicht hinderlich zu sein, da ich durch hiesige polnische Zustände und trostlose Verhältnisse gezwungen bin[,] mir wieder eine andere Brotstelle zu besorgen. Es ist traurig[,] überall wo ich mich bewerbe[,] kommt die Antwort, sie könnten mich nicht berücksichtigen. Ich will nicht annehmen[,] daß Herr General als alter deutscher Offizier einen treudeutschen Soldaten und Kriegsteilnehmer[,] welcher immer seine Pflicht getan hat[,] brotlos machen wollen. Die Vorwürfe von damals treffen mich ungerecht[.] Ich habe allerhand Bäume an Grahl und Bäcker Schuhmann abgeben müssen ohne Bezahlung[.] Ebenso sind teilweise welche gestohlen worden[,] was Frau Rudolf in Schmiede Dresslers Gegenwart anzeigte den letzten Abend[,] wie ich dort war[,] da diese ist in Richtung des Bauer Fischer gelaufen, ich fuhr früh weg und konnte den Herrn General nicht mehr melden. Für mich war es bei Herrn General Gärtner zu sein, kein beneidenswerter Posten, die Gärtnere fand ich in trostlosem Zustande vor. Wochentag und Sonntag habe ich geschuftet von früh bis spät[,] ich war immer zu Hause und auf meinem Posten. Die Herrschaften sollten mich verlangen[,] wann sie wollten[,] trotz allem wurde ich raus- geschmissen. Ich habe der gnädigen Frau alle Wünsche möglich gemacht[,] nichts war gut[.] Ich habe an Obst und Gemüse alles abgegeben[,] was möglich war die zwei Sommer[,] wo jedesmal soviel Besuch im Hause war, den Ramsch mußte ich verkaufen[,] wer gab mir dann viel dafür. Im Sommer[,] in der meisten Arbeit[,] wurden mir wochenlang sämtliche Leute genommen, ich konnte sehen[,] wie ich zu passe kam, was hat der Park für Arbeitslohn gekostet. Alles[,] was gnädige Frau wünschte[,] hieß es nur kaufen sie[,] kaufen sie, ja hatte ich kaum das Lohn zusammen und bezahlt, ging die Würgerei mit dem Gelde wieder los. Da ist meine Frau und Kinder bis Glashütte und Neugegend gelaufen[,] um das Zeug los zu werden, dafür mußte ich dann gehen zum Gaudium meiner getreuen Nachbarn[,] die da meinten[,] uns kann nichts passieren. Wir wundern uns nur zu sehr, daß da Herr General nie was erfahren tut. Ich bin weit entfernt davon[,] jemand zuverklatschen, aber das ganze Dorf war in heller Empörung[,] daß mir gekündigt wurde[.] Vielmehr hätten sie es vom Förster Hetze erwartet[,] der Trinks wollte ja alles sagen kommen. Wir wissen was Frau Hetze selber sagte[,] ihr Mann käme keinen Abend vor früh nach Haus. Sein Sohn Gerhardt kostet allein 6o Rm monatlich Pension ohne alles andere[,] einer lernt in Chemnitz und kostet viel[,] die Tochter krieg im Hause durch Herrn Lehrer König Klavierstunden. Alle erdenklichen Skatturniere u.s.w. in der ganzen Umgegend wurden mitgemacht[,] da hat sich jeder gewundert[,] wo das Geld herkommt. Mich hat nirgends Jemand gesehen[,] nicht ein einziges mal[.] Mich hat das alles nicht gestört[,] erstens hatte ich kein Geld dazu und auch mußte ich alle Tage um 4 Uhr früh raus zur Heizung[.] Wie vielmal ist es vorgekommen[,] wenn ich zur Heizung ging[,] Hetze erst vom Skatturnier oder der gleichen nach Haus kam oder manchmal[,] wenn ich um 6 Uhr früh schon das erste mal rauf ging[.] Wie oft wollte mich 
Hetze mit schleppen in die Hirschbachmühlen[,] ich habe es nicht getan. Trotzdem rühmt sich Hetze [-] er als langjähriger treuer Beamter[,] aber diese treuen Beamten hintergingen die Herrschaften am aller meisten. Ich habe stets das beste gewollt. Ich habe in Reinhardtsgrimma viel Feinde gehabt und die schlimmsten in der Nachbarschaft und mir ist vieles in die Schuhe geschoben worden. Ich bin gegangen[,] obwohl mich das sehr verbittert hat[,] aber ich möchte Herr General auch bitten [] mir nicht jetzt noch Steine in den Weg zu legen und mich brotlos zu machen. Ich habe gegen Herrn General nichts[,] sondern nur Hochachtung fü Ihn. Mit größter Hochachtung ergebenst P. Raser Gärtner. ${ }^{6}$

Die wenige Tage später verfasste Antwor des Generalmajors fällt recht nüchtern aus, über viele der angebrachten Punkte geht er wortlos hinweg. Er scheint nach wie vor davon überzeugt zu sein, dass sich allein Raser fehlerhaft verhalten hat:

»In Beantwortung Ihrer Zuschrift vom 21. Nov. habe ich Ihnen folgendes zu eröffnen. Nachdem ich sie am 21.4. davon unterrichtet habe, daß ich von Ihren Unredlichkeiten und Nachläßigkeiten Kenntniß erhalten hatte, und daß ich es bedaure Ihnen ein so gutes Zeugnis mitgegeben zu haben, stand für Sie fest, daß von dem Zeugnis keinen Gebrauch mehr machen dürften. Ich erwartete, daß sie es mir zurückstellen und um anderes bitten würden. Sie haben dies nicht getan sondern haben es an Herrschaften herumgeschickt. Sie begingen damit eine weitere Unehrlichkeit. Ich erwarte nunmehr, daß sie es mir umgehend zurücksenden und zwar Eingeschrieben, würden sie sich wohl selbst erklären können. Ich habe Interessant erscheint vielmehr sein Lebensnicht die Absicht Sie in Ihrem Beruf sagen lauf, der bereits vor der Tätigkeit in Rein sie »brotlos« zu machen. Für den Fakt ist hardtsgrimma einige Meriten aufwies. Seine in den nächsten Tagen von einem Gärtner Anstellung dort wurde wohl unter recht unSuchwerk über nähere Auskunft über Ihre schönen Umständen beendet, so dass ihn Geeignetheit gebeten worden. Verschiebe sein weiterer beruflicher Weg in die Selbst- ständigkeit führte. Ein biografischer Weg - April 1901 in der Kunst- und Handelsgärtvom angestellten Handelsgärtner, der sich nerei von August Omernick in Praust, Kreis zum Schlossgärtner hocharbeitete und Danziger Höhe, Provinz Westpreußen schließlich sein eigener Herr wurde -, der (heute Pruszcz Gdański, powiat gdański, gewissermaßen auch als Abbild gesellschaft- województwo pomorskie) durchlief. Dort licher Veränderungen in der ersten Hälfte war er zudem ein weiteres Jahr als Gehilfe des 20. Jahrhunderts gesehen werden kann. ${ }^{65}$ ätig. Laut Lehrzeugnis erlernte er dabei den Umgang mit Topfpflanzen, die Gemüsetrei-

Gärtner Hinz bewarb sich mit einem am 8. berei, den Baumschnitt sowie die Bindere Februar 1927 in Rogau, Kreis Liegnitz, Pro- und hatte »die volle Zufriedenheit [seines vinz Schlesien (heute Rogów Legnicki, po- Lehrmeisters] erworben «. ${ }^{68}$ wiat legnicki, województwo dolnośląskie) verfassten und an Maximilian Senfft von Pil- Die anschließende vierjährige (2. April 1902 sach gerichteten Schreiben. Darin teilte er bis 30. März 1906) Fortbildung zum »Untermit, dass er zum Zeitpunkt der Bewerbung gärtner « absolvierte Hinz in der Frei42 Jahre alt, verheiratet und kinderlos sei. herrl[ich] Dungern'schen Schlossgärtnerei Die Auskunft darüber, dass in Reinhardts- des hessischen Schlosses Dehrn bei Limburg grimma ein Gärtner gesucht werde, habe er an der Lahn, das über einen Landschaftsgardurch »Herrn Kramer Breslau« erhalten, ten verfügte. Sein Ausbilder, der Obergärtebenjenen Stellenvermittler, über den auch ner Hoffmann, beschrieb ihn in seinem schon Paul Raser nach Reinhardtsgrimma Zeugnis als "umsichtig und geschickt«. Er gelangte. Zudem berichtete Hinz über sei- habe sich in seiner dortigen Anstellung der nen Werdegang:

»Geboren im Kreise Danzig trat ich mit 14 Jahren in die Lehre. Nach dreijähriger beendeter Lehrzeit war ich zu meiner weiteren Ausbildung als Untergärtner in einer erstklassigen Schloßgärtnerei in Süddeutschland tätig, wo ich mir recht gründliche Kenntnisse erworben habe, auch fand ich dort Gelegenheit mir den Formobstschnitt nach dem System des berühmten Süddeutschen Pomologen Christ Lucas, Direktor des Pomologischen Instituts in Reutlingen anzueignen. ${ }^{66}$ Bin durchaus selbstständig und selbsttätig. In meiner letzten Stellung als Schloßgärtner bin ich 5 Jahre bei Herrn von Rother auf Rogau, Ober- und Nieder Koitz im Kreis Liegnitz gewesen. [...] $\ll^{67}$

Seinem Bewerbungsanschreiben legte Hinz zudem Zeugnisabschriften bei, die erkennen lassen, dass mit ihm ein hervorragend ausgebildeter Gärtner nach Reinhardtsgrimma kam. So geht aus den Zeugnissen hervor, dass Hinz die in der Bewerbung erwähnte Gärtnerlehre vom 1. April 1898 bis zum 1.
Vermehrung und Anzucht von Gewächshauspflanzen, sowie der Anlage und Bepflanzung von Teppich- und Blumenbeeten gewidmet und verließ die Stellung auf eigenen Wunsch. ${ }^{6}$

Darauf folgte vom 1. Mai 1906 bis zum 30. September 1907 eine kurze Anstellung als Gärtner in Berlin-Lankwitz bei Herrn Friedrich Correns (1863-1923), dem damaligen Direktor der Berliner Akkumulatorenfabrik Aktiengesellschaft. ${ }^{70}$ Der dortige circa 3,7 Hektar umfassende Park gehörte zu einer nach Plänen von Fritz Freymüller (18821950) errichteten Villa (heute Calandrelli-/ Gärtnerstraße) und wurde vom Berline Gartenarchitekten Carl Rimann (1870-1947) angelegt. Park und Villa sind heute noch erhalten und stehen seit 1988 unter Denkmalschutz. ${ }^{71}$ Hinz war hier mit der Überwachung des Treibhauses, der Frühbeete, des Obst- und Gemüsegartens sowie der Anlage von Wegen und Rasenplätzen betraut. Auch hier erfolgte eine positive Einschätzung seiner Person als »fleißig und willig«. 


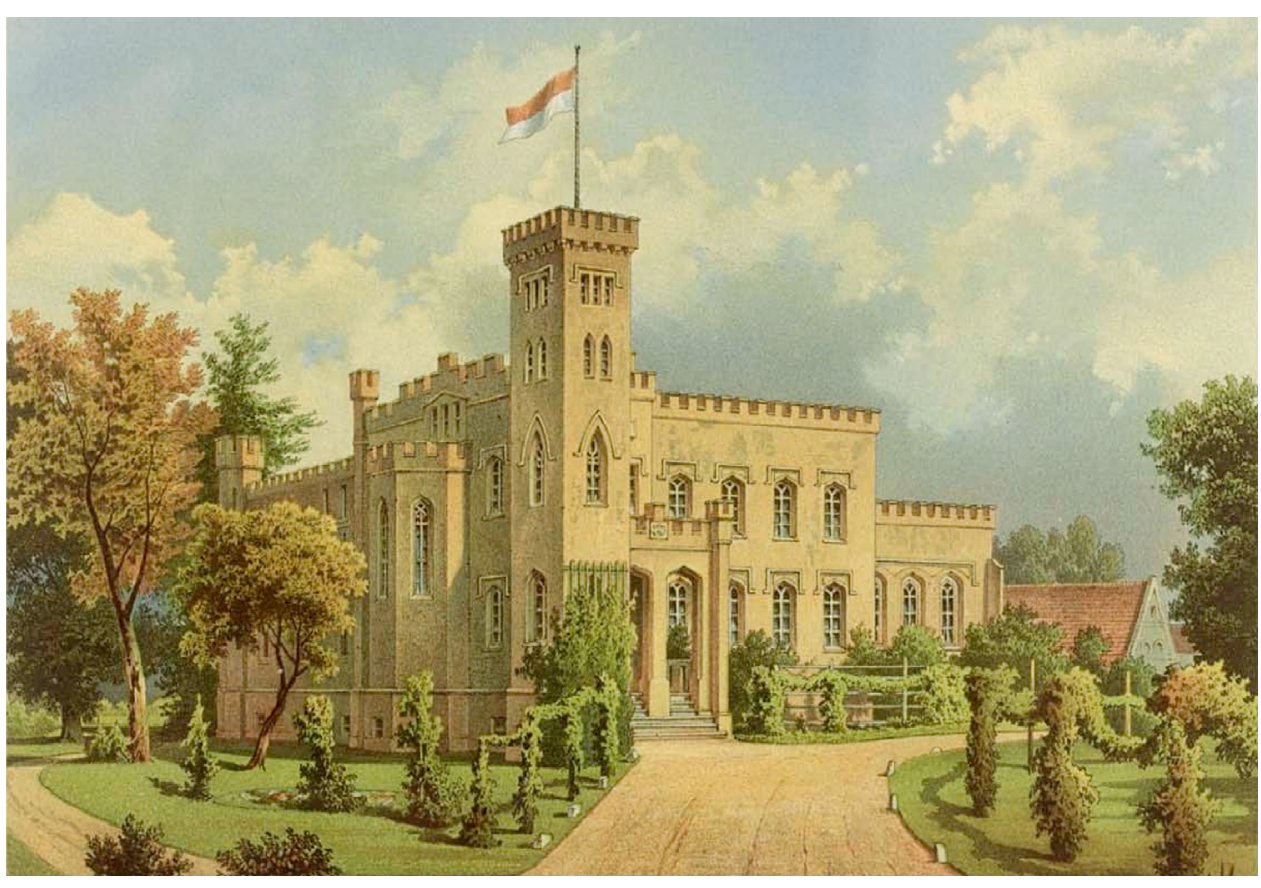

5 | Ansicht von Schloss und Garten Lankau, Farblithographie von Winckelmann und Söhne nach einer Zeichnung von Ernst Friedrich von Stowerroffsky (aus Duncker, Alexander: Die ländlichen Wohnsitze, Schlösser und Residenzen der ritterschaftlichen Grundbesitzer in der preußischen Monarchie nebst den Königlichen Familien-, Haus-Fideicommiss- und Schatullgütern, Band 9, Berlin 1866/67, S. 191).

In den drei darauffolgenden Jahren - vom 1. treute er die "Musterformobstanlage, gröOktober 1907 bis zum 1. Oktober 1910 - war ßere Frühbeettreiberei für Gemüse, 2 TreibHinz als Gärtner am »Obst- und Teichgut « häuser, 1 kleiner Park mit Teppich- und Bluim oberpfälzischen Thansüß (bei Freihung) menbeeten«. In seinem lobenden Zeugnis beschäftigt, dem Landgut des Nürnberger sind auch seine Ambitionen vermerkt: »ehrFabrikbesitzers Oskar Strahser. Ihm oblag lich, gute Führung, verlässt Stellung, um dort die Unterhaltung und Pflege des circa größerem Betriebe vorzustehen «.73 2.00o Bäume umfassenden Obstgartens so-

wie die Neukultivierung und Anlage von Der Aufstieg zum Schlossgärtner gelang Gemüsekulturen. Er wurde aufgrund »bes- ihm mit seiner nächsten Anstellung: Für tem Geschicks « weiter empfohlen. ${ }^{72}$ achteinhalb Jahre (1. Oktober 1913 bis 1. Jun 1922) bekleidete er diese Position bei Baron Wiederum für drei Jahre (1. November 1910 von Stosch in Lankau, Kreis Namslau, Probis 30. September 1913) war Hinz für Dr. vinz Schlesien (heute Łączany, powiat Heinrich Jordan, Fabrikbesitzer und Hoflie- namysłowski, województwo opolskie) (Abb. ferant ihrer Majestät der Kaiserin (Auguste 5). Dort versorgte er "Glashausanlagen Viktoria von Schleswig-Holstein-Sonder- Obst- und Gemüsegarten, Park«. Stosch beburg-Augustenburg, 1858-1921), als Ober- scheinigte Hinz ein »besonderes Interesse gärtner in dessen Villengarten (Villa Jordan für Baumschnitt und Pflege« und erwähnte

- heute Unterm Hain 13) im thüringischen lobend: er »zog Blumen für [das] Schloss Rudolstadt tätig. In diesem parkähnlichen und gruppierte sie in den Zimmern und [beVillengarten mit Orangerie am Hang be- wies] dabei Geschmack in Bukett und Tafel- dekoration«. Hinz sei »energisch, solide, zuverlässig, umsichtig « und wird als »erfahren in seinem Fach« beschrieben - was angesichts seines beruflichen Werdegangs wenig verwundern kann. Die Beendigung dieser Anstellung erfolgte wiederum auf Hinz' eigenen Wunsch.74

Seine letzte Bestallung, bevor er in die Dienste Maximilian Senfft von Pilsachs trat, hatte Hinz - wie er selbst in seiner Bewerbung bemerkt - für fünf Jahre (1922-1927) in Rogau sowie in Koitz, Kreis Liegnitz, Provinz Schlesien (heute Kawice, powiat legnicki, województwo dolnośląskie) bei den Herren von Rother inne. In Fragen der Gartengestaltung wurde dort vermutlich Peter Joseph Lenné (1789-1866) zu Rate gezogen. Zumindest für das Gut Koitz existiert ein Plan von Lenné, der um 1840 entstanden ist. $^{75}$

Die vermutlich schon infolge des Ersten Weltkriegs wirtschaftlich geschwächte $\mathrm{Fa}-$ milie sah sich nach dem Tod des kinderlosen Familienoberhauptes, Willy von Rother (1870-1927), gezwungen, sowohl Parkpflege als auch Gemüsekultivierung einzuschränken. Da zudem bereits ein älterer Gemüsegärtner beschäftigt wurde, gab es für Hinz keine Arbeit mehr, woraufhin er sich auf eine Gärtnerstelle in Reinhardtsgrimma bewarb.

Vermutlich wandte sich Alpheda Senfft von Pilsach (Abb. 6) an die verwitwete Ruth Karoline Sigunda von Rother, geborene von Schweinitz, (1877-?), Hinz' vorherige Arbeitgeberin, um sich tiefer gehende Informationen über Hinz einzuholen. Zumindest legt dies ein Schreiben von Frau von Rother an Alpheda Senfft von Pilsach vom 16. Februar 1927 nahe: der Gärt- Schriftwechsel zwischen Hinz und Senfft ner ist fein entlassen, weil der Gartenbetrieb ganz eingeschränkt wird. Er ist ein vorzüglicher Gärtner, Glashaus, Frühbeete, alle Treibereien sind seine Spezialität. Er ist sehr höflich und anständig im Umgang, durchaus national in seiner Ge-
Auf das Bewerbungsanschreiben folgte ein

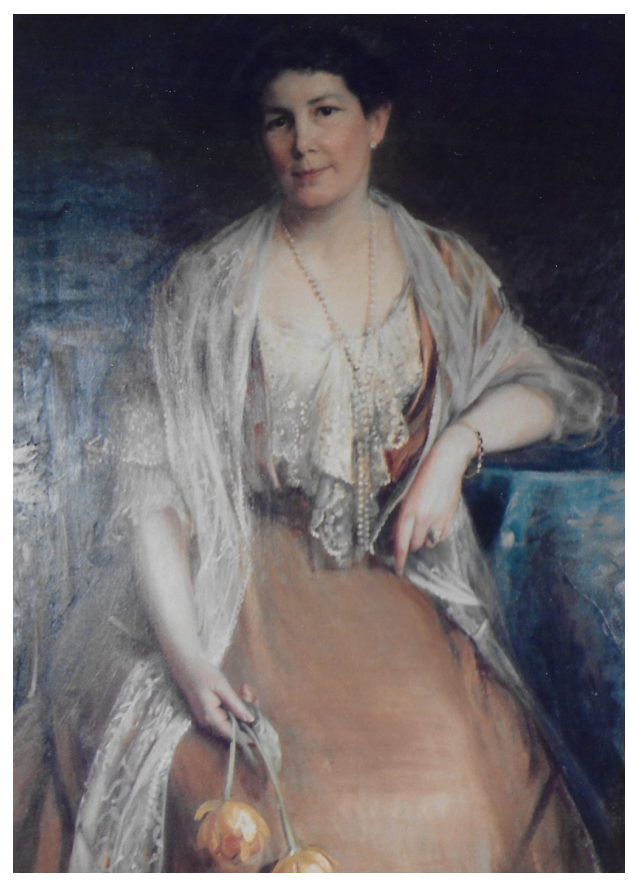

6| Alpheda Louise Teding van Berkhout (1863-1959) Olportrat, Urheber unbekannt, heute in Schloss Planta/ Meran (Fotografie: Privatarchiv von Friesen).

sinnung. Seine Frau ist hier nicht mit tätig gewesen, ob sie sich in einer neuen Stellung dazu verpflichten würde, weiß ich nicht. So viel mir bekannt ist, ist Hinz gesund wenigstens ist er hier nie krank gewesen. Da ich mich persönlich viel um den Garten gekümmert habe, kann ich nicht genau beantworten, wie Hinz ganz ohne alle Anregung arbeiten würde, ob man seinen Geschmack nicht doch manchmal unterstützen müßte? Er hat hier alle Tisch und Blumenarrangements gemacht aber doch nach Angabe, Ihre Ruth von Rother. «7 von Pilsach, der in Teilen erhalten geblieben ist. Darin ließ Hinz Selbstbewusstsein erkennen, indem er einige Ansprüche bezüglich der Bedingungen der Anstellung formulierte. So forderte er einen Gehilfen statt ei- 
»Sonntags nach Feierabend zur Hand gehen den Beweis dafür bis zum 1. Juli 1928 erbrinmuß«, und etwas subtiler weitere Hilfs- gen, da ansonsten die Kündigung erfolge. ${ }^{79}$ kräfte:

Diesen Beweis blieb Hinz offenbar schuldig die Kündigung erging am 2. Juli 1928 und "Auch die Zentralheizung würde ich wurde mit mangelnder Parkpflege und unübernehmen, jedoch nehme ich an, daß gebührlichem Verhalten begründet. ${ }^{80}$ mir auch Hilfskräfte zur Verfügung stehen.

Hinz bestritt jedoch, dass eine schriftliche Kündigung an ihn ergangen sei. Eine Aussprache mit Wolf Erich von Schönberg

Zudem gehen aus dem Schriftwechsel Infor- (1895-1981), dem Schwiegersohn des Genemationen zu seiner vorherigen Anstellung, ralmajors Senfft von Pilsach, der in dessen den dortigen Gegebenheiten und letztlich Auftrag handelte, soll er - nach Darstellung seiner Befähigung hervor:

»Ich hatte hier für den 30 Morgen großen Park mit reichem Blumenparterre, große Rhododendron-Gruppen, Rosenrabatten, viele Gewächshauskulturen 2 Lehrlinge, ein Gartenmann und 3 Frauen zur Hilfe. Einen Lehrling der schon $1 \frac{1}{2}$ Jahre gelernt hat könnte ich mitbringen. Er bekommt frei Kost und Wohnung sowie monatlich 6 Mark. Mehrere Hühner konnte ich mir halten, aber kein Schlachtschwein, ich bekam das fertig von der Wirtschaft.«t

Hinz war also durchaus in der Lage einen großen Garten mit reichhaltigem Blumenschmuck zu versorgen sowie Arbeiten zu organisieren und zu delegieren - und er scheint sich seines Könnens sehr bewusst gewesen zu sein.

Hinz Anstellung in Reinhardtsgrimma endet - wie eingangs erwähnt - anders als seine vorherigen Dienstverhältnisse, unter unschönen Umständen. So teilt Alpheda Senfft von Pilsach, die wohl zu diesem Zeitpunkt bereits die Geschicke auf Reinhardtsgrimma lenkte ${ }^{78}$, ihm Mitte Mai 1928 mit, dass eine offenbar kurz zuvor ausgespro- Senfft von Pilsach zahlte insgesamt 525 chene Kündigung wegen mangelnder Ver- Reichsmark an Hinz. ${ }^{85}$

sorgung des Obst-, Gemüse- und Blumen-

gartens vorerst zurückgezogen werde. Hinz Trotz aller Streitigkeiten wird Hinz am 1. müsse ebendiese Gärtnerei, den Blumengar- November 1928 ein wohlwollendes Zeugnis ten und den herrschaftlichen Friedhof je- ausgestellt, in dem Generalmajor Senfft von doch fortan zu ihrer vollsten Zufriedenheit Pilsach einen neutralen Kündigungsgrund bepflanzen und in Ordnung halten sowie formuliert: Der Gärtner habe die Stelle ver- lassen müssen, da die »Gärtnerei einer Umstellung unterzogen wird ${ }^{86}$. Der eigentliche Grund für Hinz' Pflichtversäumnisse und sein ungebührliches Verhalten in deren Nachgang gehen aus den Quellen nicht hervor.

Hinz machte sich später mit einem eigenen Gartenbaubetrieb in Falkenberg/Mark bei Eberswalde selbstständig - und somit unabhängig von jeglichen Dienstherren. ${ }^{87}$ Eventuell kam ihm dabei die Vergleichszahlung zupass. An seinem Verhalten, gerade auch im Zusammenhang mit den Vorgängen um seine Entlassung, lässt sich durchaus ein erstarkendes Selbstbewusstsein des Gärtners und das Schwinden der Autorität des adligen Grundbesitzers ablesen.

\section{Georg Karliczek (Tätigkeitszeitraum}

Oktober 1928 bis März 1939)

Am 20. Juli 1928 schaltete Wolf Erich von Schönberg im Auftrag seines Schwiegervaters Generalmajor Maximilian Senfft von Pilsach eine Stellenanzeige in einer Gärtnerzeitung. ${ }^{88}$ Gesucht wurde ein herrschaftlicher Gärtner im Alter von 28 bis 45 Jahren. Er sollte in Obst- und Gemüsebau, Blumentreiberei sowie Parkpflege erfahren sein und eine Gärtnerei von circa einem Hektar leiten können. Auf diese Anzeige meldeten sich innerhalb von acht Tagen 65 Bewerber, teilweise sogar aus dem Ausland. ${ }^{89}$ Senfft von Pilsach und von Schönberg entschieden sich für den 1900 geborenen Georg Karliczek (Abb. 7). Anfang September desselben Jahres erhielt er, nach vorherigen mündlichen und schriftlichen Absprachen, seinen Anstellungsvertrag per Post und trat seinen Dienst am 1. Oktober 1928 an..${ }^{\circ}$

Geboren wurde Karliczek am 26. Juli 1900 in Niewodnik (zwischen 1936 und 1945 Fischbach O.S. genannt), Kreis Falkenberg O./S., Provinz Schlesien (heute Niewodniki, powiat opolski, województwo opolskie). Zum Rittergut in Niewodnik gehörte auch eine um 1870 angelegte, große landschaftliche Parkanlage (Abb. 8), sodass Karliczek ver-

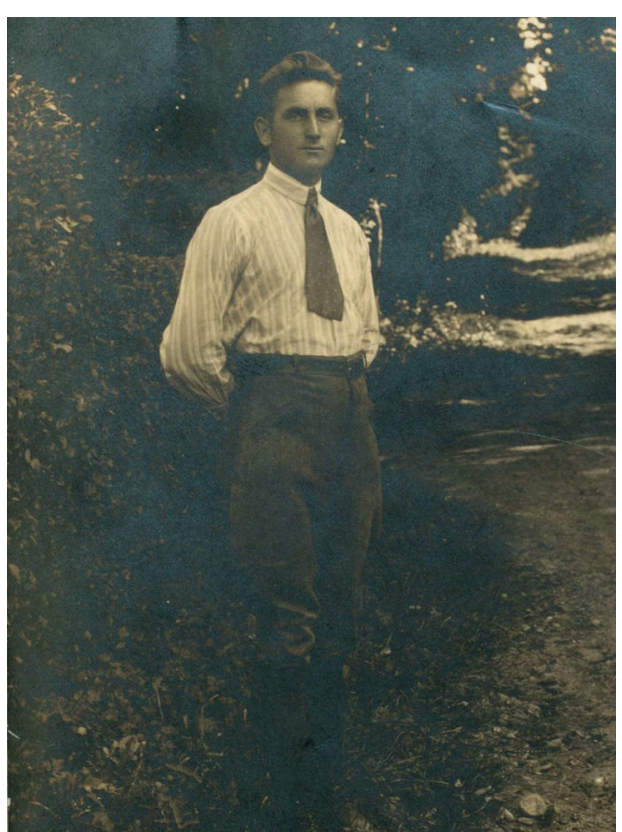

| Georg Karliczek, Schwarz-Weiß-Fotografie, um 1928. Dieses Foto lag Karliczeks Bewerbung für die Gärtnerstelle in Reinhardtsgrimma bei (SächsHStA, 10505, Nr. 127).

mutlich bereits in Kindheitstagen mit der Gartenkultur in Berührung kam.

Seine erste Stelle als Gartengehilfe trat Karliczek am 15. März 1922 in der von Arnim'schen Gartenverwaltung in Gerswalde in der Uckermark an. Felix Wilhelm Friedrich von Arnim (1862-1919) und seine Ehefrau Emily (1869-1952) veranlassten zwischen 1907 und 1912 den Umbau des Gerswalder Herren hauses und erweiterten den Gutspark zusammen mit der Gärtnerei. ${ }^{91}$ Auf dem Gelände wurde Wein in einem Weinhaus angebaut, es gab einen Obst- und Gemüsegarten ein Kalt- und ein Warmhaus sowie ein Palmenhaus. Auf Obstterrassen ließ Emily von Arnim kalifornisches Tafelobst anbauen. ${ }^{92}$ Hier verbrachte Karliczek als Gehilfe unter Obergärtner Wilhelm Weichard seine ersten Arbeitsjahre. Weichard beschrieb Karliczek als treu, ehrlich und fleißig und lobte sein moralisches Wohlverhalten. ${ }^{93}$ Er verstand sich auf den Obstbau, die Wein-, Pfirsich- 


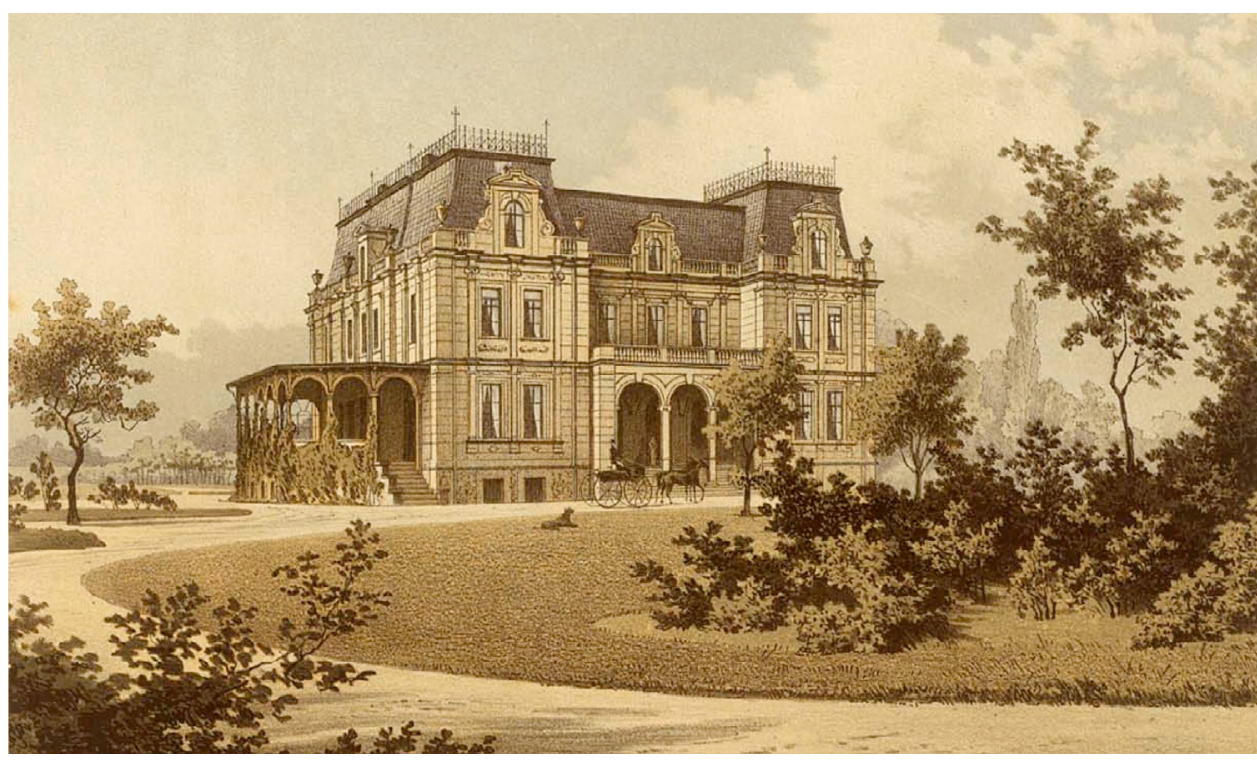

8| Ansicht von Schloss und Garten Niewodnik, Farblithographie von Theodor Albert nach einer Zeichnung von Theodor Blätterbauer (aus Duncker, Alexander: Die ländlichen Wohnsitze, Schlösser und Residenzen der itterschaftlichen Grundbesitzer in der preußischen Monarchie nebst den Königlichen Familien-, Haus-Fideicommissund Schatullgütern, Band 15, Berlin 1878/80, S. 57).

und Gemüsetreiberei, die Pflege von Topf- bracht und musste einen Großteil des Besitpflanzen, Orchideen, Palmen, Cyclamen zes an die Landwirtschaftliche Siedlungsge(Alpenveilchen) und Chrysanthemen. Des meinschaft "Eigene Scholle« verkaufen, die Weiteren war er für die Dekoration des Her- überregional größere Flächen erwarb, um renhauses und die Parkpflege zuständig. ${ }^{94}$ diese dann parzelliert zu veräußern. ${ }^{97}$

Die Gärtnerei Gerswalde war eine aner- Von Arnim beschrieb Karliczek als anstänkannte Ausbildungsstätte für den Gärtner- dig, tüchtig und fleißig. Weiterhin bestätigte beruf. Karliczek als Gehilfe hatte als unmit- er dessen Fachverstand. Dabei nannte er telbarer Vorgesetzter der Lehrjungen Anteil beispielhaft Aufgaben wie Frühtreiberei, an deren Ausbildung. 95 "Mit eiserner Ener- Obstschnitt, Kranzbinderei und Tafeldekogie « hat er sie zur Arbeit angehalten und »ta- ration. Interessant ist, dass Karliczeks natiodellos erzogen «. ${ }^{96}$ So schrieb der Sohn der nale Gesinnung hervorgehoben wurde. Er Eigentümer - Adolf Oswald von Arnim hatte im schlesischen Grenzschutz mitge(1890-1970) - an den Rittergutsbesitzer kämpft und war »eifrigstes Mitglied « des Hans Wichard von Rochow-Stülpe (1898- Wehrverbandes »Stahlhelm, Bund der 1945) als dieser Erkundigungen über Karli- Frontsoldaten $«{ }^{98}$ Von Arnim dürfte Karliczek einholte. Anlass war Karliczeks ange- czeks Gesinnung nicht ohne Grund angedachter Wechsel auf eine Gehilfenstelle in führt haben. Auch Hans Wichard von Roder Schlossgärtnerei Stülpe bei Luckenwalde chow-Stülpe war seit 1923 Mitglied des (Abb. 9). Vermutlich musste sich Karliczek Stahlhelms. ${ }^{99}$ So verfügte Karliczek über eine neue Anstellung suchen, da Adolf Os- seine fachliche Eignung hinaus über eine wald von Arnim das Gut Gerswalde 1926 weitere Qualifikation für eine Stelle in verlor. Er hatte sein Vermögen und sein Stülpe. Von Rochow-Stülpe und sein OberErbe durch Fehlspekulationen in Gefahr ge- gärtner M. Schleutz ${ }^{100}$ waren wohl von Kar-

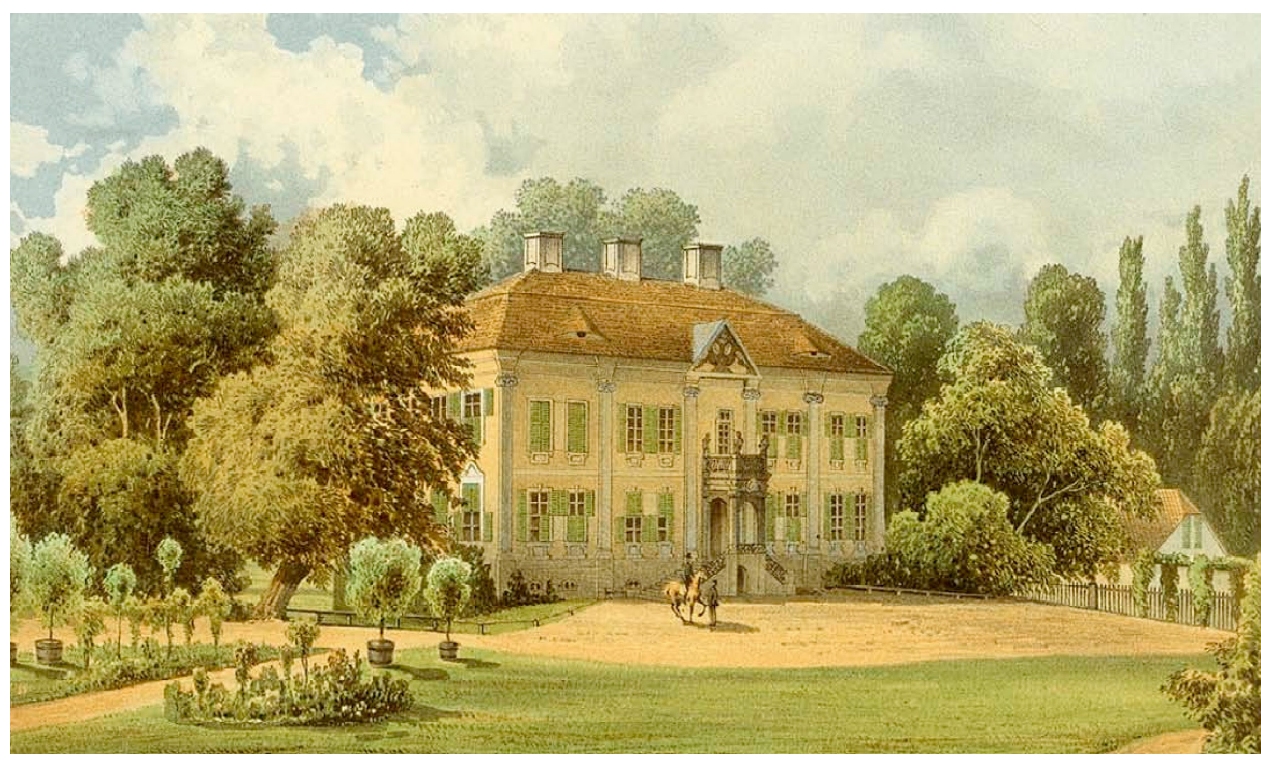

9 | Ansicht von Schloss und Garten Stülpe, Farblithographie von Theodor Albert nach einer Zeichnung von Hartmann (aus Dunckers Alexander: Die ländlichen Wohnsitze, Schlösser und Residenzen der ritterschaftlichen Grundbesitzer in der preußischen Monarchie nebst den Königlichen Familien-. Haus-Fideicommiss- und Schatullgütern, Band 2 Berlin 1859/60, S. 227).

liczeks Eignung überzeugt, denn am 1. September 1926 verließ dieser Gerswalde und nahm vermutlich ab dem 1. Oktober 1926 eine Gehilfentätigkeit in der Schlossgärtnerei Stülpe auf. Hier fand er ein altes Familienanwesen mit dem 1754 von Adam Ernst II. von Rochow-Stülpe (1705-1759) erbauten Schloss vor. ${ }^{101} 1820$ wurde unter Adolf Friedrich August von Rochow-Stülpe (1788-1869) ein Landschaftspark angelegt, in dem sich auch botanische Kostbarkeiten befanden. ${ }^{102}$ Circa 1920 ließ Hans Wichard von RochowStülpe die gebäudenahen Partien des Parks neobarock überformen.

Karliczek blieb nur eineinhalb Jahre in Stülpe. Er verließ die Schlossgärtnerei im Sommer 1928 mit einer guten Einschätzung von Obergärtner Schleutz. ${ }^{10}$

Bevor in Reinhardtsgrimma ein neuer Gärtner beschäftigt werden sollte, wurde ein $\mathrm{Fa}$ milienrat abgehalten. Wolf Erich von Schönberg formulierte in einem Brief an Generalmajor Senfft von Pilsach:
»Wir wollen zusammen den Garten ein richten und ich will ihnen dabei helfen, da ich genügend eigene Erfahrungen darin gesammelt habe. [...] Es würde mir direkt eine Freude machen, Euch einen Mann einzurichten, der nett, fleißig und anständig ist und der aus dem Garten das macht, was möglich ist. $\ll^{104}$

Von Schönberg und Senfft von Pilsach legten verschiedene Rahmenbedingungen für den neuen Gärtner fest - 2270 Reichsmark durften für die Gärtnerstelle pro Jahr aufgewendet werden. ${ }^{105}$ Eingerechnet waren die ährlichen Kosten für Naturalien in Höhe von 1080 Reichsmark, 120 Reichsmark Miete für eine Wohnung und 50 Reichsmark für das Licht. Hinzukommen sollte ein Gärtnergehalt von 85 Reichsmark pro Monat. Die Gesamtausgaben für den Gärtner betrugen also monatlich 189 Reichsmark. Von Schönberg nahm die Einstellung und Kontrolle des neuen Angestellten seinem 74-jährigen Schwiegervater ab. Er schlug einen klaren Anstellungsvertrag vor, dem eine Dienstan- 
weisung beigelegt werden sollte. Zusätzlich in Aussicht gestellt. Karliczek entschied sich wollte er vom neuen Gärtner eine Kaution für Kurt Müller (1907-?) einen geprüften von 500 Reichsmark und das Führen eines Gartenbautechniker, der eine dreijährige Kassen-, eines Inventar- und eines Lieferbu- Ausbildung zum Gehilfen in der renomches für die Küche verlangen. ${ }^{106}$ Die Abrech- mierten Gärtnerlehranstalt Oranienburg bei nung hätte monatlich zu geschehen und Berlin absolviert hatte. ${ }^{107}$

sollte dem Güterdirektor Curt Schübner beziehungsweise von Schönberg persönlich je- Über die Schwierigkeiten mit seinem Vorden Monat übermittelt werden. Eine Kau- gänger war Karliczek informiert, so schreibt tion war durchaus üblich und wurde sogar von Schönberg an Senfft von Pilsach: im »Tarifvertrag zwischen der sozialen Abteilung des Sächsischen Landbundes und dem Deutschen Gartenverband « in der Fassung von 1925 niedergeschrieben. Von Schönberg schlug vor, die Anbaufläche, die tatsächlichen Einnahmen, die Lieferungen ins Schloss und den Arbeitskräfteverbrauch persönlich zu kontrollieren. Im Vergleich zu den Arbeitsbedingungen der vorherigen Gärtner in Reinhardtsgrimma unter Generalmajor Senfft von Pilsach, wurde nichts dem Zufall überlassen. Der Grund dafür dürfte in den negativen Erfahrungen mit Karliczeks Vorgänger Joseph Hinz liegen.

Die erweiterten Anforderungen an einen Schlossgärtner in Reinhardtsgrimma waren für Karliczek kein Grund für eine Absage. Bereits im August 1928 hatte er seine neue Stelle sicher. Nach vorherigen mündlichen Absprachen nahm er diese am 28. August 1928 offiziell an. Sein Gehalt wurde von 85 auf 100 Reichsmark im Monat erhöht. Vermutlich, um die Gärtnerstelle für ihn attraktiver zu machen und den zusätzlichen Arbeitsaufwand auszugleichen. Per Brief wurde nun alles Weitere geklärt. Der 28-jährige Karliczek wollte gern heiraten. Ab Januar 1929 sollte darüber entschieden werden, ob ihm die Herrschaft eine Heirat erlaubte. Dies war abhängig von seiner Tätigkeit als Gärtner, seinen Leistungen und seiner Führung. Im Falle einer Heirat würden Deputat und Gehalt angepasst werden. 150 Reichsmark wurden in Aussicht gestellt. Einen Gehilfen konnte sich Karliczek selbst aussuchen und möglichst bei Dienstantrit im Oktober gleich mitbringen. Diesem wurde ein Gehalt von 40 bis 45 Reichsmark

»Ich hielt es für richtig, ihn über die Schwierigkeiten mit seinem Vorgänger aufzuklären, damit er es vorher weiß und nicht sofort von allen Leuten vorgesetzt bekommt. ${ }^{108}$

Am 8. September 1928 versendete von Schönberg Karliczeks Anstellungsvertrag per Post und informierte ihn darüber, dass die Wartung und das Anstellen der Zentralheizung des Schlosses ebenfalls in seinen ungabenbereich fielen. Außerdem schrieb er:

»Ich möchte nicht unterlassen, Ihnen mitzuteilen, dass der Abgang ihres Vorgängers mit sehr grossen Unannehmlichkeiten verbunden ist. Dem Mann [Hinz] ist alles zuzutrauen, um Ihnen den Antritt zu erschweren. Wir setzen aber alles daran, dass er auch die Wohnung räumt, was ich erwarte. Sie werden aber auch trotzdem gut untergebracht und sie sollen es so haben, dass sie sich wohlfühlen. $\aleph^{109}$

Von Schönbergs Erwartung erfüllte sich nicht. Als Karliczek am 1. Oktober 1928 einziehen wollte, hielt Hinz das Gärtnerhaus besetzt. Karliczek zog stattdessen am Tag darauf zunächst in das Forsthaus. Der Güterdirektor Schübner übergab ihm eine Zweiraumwohnung, die mit allem Nötigen ausgestattet war, sodass sich Karliczek durchaus gut einrichten konnte. Aus einem Inventarverzeichnis von 1928 geht plastisch hervor wie die Wohnung eingerichtet war: »1stes Zimmer.

monatlich 73,15 Reichsmark betragen (Tarif-
- ein großes

decke.

- ein gewöhnlicher viereckiger Tisch aus Tannenholz braun gestrichen

- drei gelbe Stühle mit Rohrsitz

- ein dunkel gebeizter Schreibtisch mit Seitenschränkchen

- ein braun gestrichener Kleiderschrank. Tannenholz

- ein Kleideranhänger an der Wand (Hufeisenform)

vertrag \$8 B: Bargehalt). Sein Deputat wollte Karliczek in Naturalien erhalten. Darauf wurde eingegangen. Ab dem 1. Dezember 1928 bekam - der nun doch bereits verheiratete $^{111}$ - Gärtner Karliczek ein Gehalt von 120 Reichsmark und dazu ein Deputat für zwei Personen. Das Gehalt war also deutlich höher als tariflich vorgeschlagen, fiel jedoch geringer aus als die in Aussicht gestellten 150

- ein Bild (Jagd von König Albert in sich folgendermaßen zusammen: Schandau)

- eine rot-weiße Tischdecke

- ein Kohlenbehälter mit Schaufe

\section{2tes Zimmer.}

- zwei gelbe Stühle mit Rohrsitz

- neun Zentner Roggen

- drei Zentner Weizen

- fünf Zentner Hühnergetreide (Hafer, Gerste oder Weizen)

- 36 Zentner Speisekartoffeln

ein braun gestrichenes Holzbett mit • zehn Zentner Futterkartoffeln Drahtmatratze, dicke Strohmatratze, • zwei Zentner Äpfel und Birnen Unter- und Oberbett, Kopfkissen. Und - ein Zentner Beeren und Steinobst Keilkissen

- ein brauner Tannenholz Nachttisch mit weiss lackierter Platte

- ein weißer eiserner Waschtisch

- eine Blech-Waschkanne, weiß

- eine Blech-Waschschüssel, weiß

- ein Seifennäpfchen, weiß

- eine Zahnbürstenschale, weiß

- ein Wasserglas

- ein brauner Emailleeimer

- ein Blech-Nachttopf, weiß

- eine Tannenholz-Kommode mit dre Schubfächern

- ein kleiner Spiegel mit brauner Umrahmung

- eine Kommodendecke «110.

Bis zum 26. November 1928 wurde über Karliczeks Gehalt und Deputat verhandelt. Der letztendliche Anstellungsvertrag orientierte sich am 1925 festgelegten Tarifvertrag (Abb. 10). So stand ihm nach $\$ 6$ des Tarifvertrages ein Gesamtjahreseinkommen zu, das sich aus einem Bargehalt und Naturalbezügen oder freier Logis zusammensetzte. Gemäß Gruppe III des Gutsbeamtentarifes vom 28 . Juli 1924 sollte das Bargehalt eines Gärtners
- täglich zwei Liter Milch.

Butter bekam er ausdrücklich nicht, da dies, wie Generalmajor Senfft von Pilsach schrieb, "in den Kriegszeiten abgeschafft wurde «." Hinsichtlich der Mengenangaben wich Karliczeks jährliches Deputat in einigen Punkten vom Tarifvertrag ab. So erhielt er vier Zentner weniger Speise- und fünf Zentner weniger Futterkartoffeln, dafür jedoch zwe Zentner mehr Getreide und sogar Futter für die Kleintiere. Mit zwei Zentnern Äpfeln und Birnen sowie einem Zentner Beeren und Steinobst erhielt Karliczek deutlich mehr als die tariflich für einen verheirateten Gärtner vorgesehenen 450 Pfund an Obst und Beeren. ${ }^{113}$ Auch an Milch wurden ihm täglich zwei Liter anstatt eines Liters zugestanden. Vermutlich wurde das Deputat an die Ernteerzeugnisse des Gutes Reinhardtsgrimma angepasst

Außerdem durfte er sich "zwölf Hühner vier Enten oder Gänse (eingezeunt) und zehn Kaninchen in Ställen " halten. ${ }^{114}$ Laut Tarifvertrag sollte dies »tunlichst gestattet werden«. Dazu kam ein Schwein, für das er 15 Reichsmark Ablöse pro Monat erhielt. 

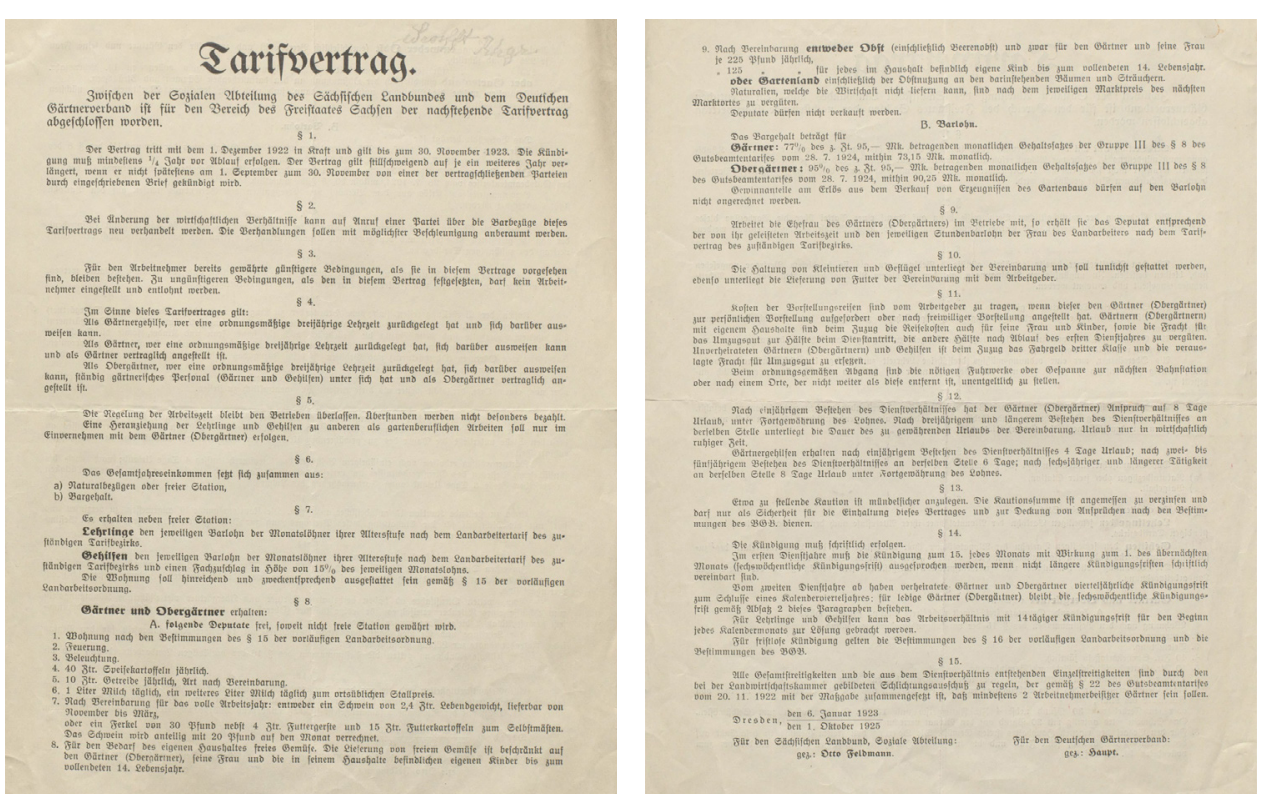

10 | Tarifvertrag zwischen der sozialen Abteilung des Sächsischen Landbundes und dem Deutschen Gartenverband « in der Fassung von 1925 (SächsHStA, 10505, Nr. 272, Anstellungs- und Tariffragen des Gärtners Karliczek 1928).

Wohnung, Licht, Gemüse und Briketts zum Karliczeks Aufgabenbereich erstreckte sich Heizen wurden ihm, wie 1925 im Tarifver- von der Pflege der Schlossgärtnerei, über trag festgeschrieben, kostenlos überlassen. den Park und die zum Rittergut gehörenden

Kündigen durfte Karliczek laut Anstel- Obstbäume bis hin zu den Bienenstöcken lungsvertrag in den ersten drei Tagen nach und Gewächshäusern. Die Einstellung und dem Quartalsersten mit einer vierteljährli- Entlassung von Gartengehilfen und Gartenchen Frist, eine fristlose Kündigung konnte frauen konnte nur mit Zustimmung der nur nach \$16 der Landarbeitsordnung ge- Gutsherren geschehen.

schehen. ${ }^{115}$ Der Kündigungsfall seitens der Gutsherrschaft fiel zu seinen Gunsten aus, Während seines Beschäftigungsverhältnisda ihm bereits bei Dienstantritt eine Kündi- ses in Reinhardtsgrimma hielt Karliczek regungsfrist von drei Monaten und nicht, wie gen Briefkontakt mit von Schönberg und inim Tarifvertrag niedergeschrieben, von le- formierte ihn monatlich über die verrichtediglich sechs Wochen zugestanden wurde. ${ }^{116}$ ten Arbeiten in der Schlossgärtnerei.

Nach seinem ersten Arbeitsjahr hatte er An- Der Jahresbeginn 1929 war bitter kalt. Karlispruch auf sechs Tage Urlaub, nach dem czek berichtete von Schönberg in einem zweiten Jahr auf zehn und nach dem dritten Schreiben, dass die Gewächshäuser bei -34 auf zwölf Tage. In $\$ 12$ des Tarifvertrages Grad Celsius Außentemperatur Tag und heißt es hingegen, dass ein Gärtner bereits Nacht beheizt werden mussten und so bein seinem ersten Dienstjahr acht Tage Ur- reits das Holz knapp werde. Auch die Rinde laubsanspruch habe. Nach drei Jahren könne der Linde vor dem Schloss sei geplatzt. Der dann die Anzahl der Urlaubstage neu ver- Gehilfe Müller hatte wahrscheinlich alle einbart werden. Zudem war Karliczek kran- Hände voll zu tun, die Zentralheizung im ken- und invalidenversichert. Die Kosten Schloss zu betreuen. Im Februar verließ er trugen er und sein Dienstherr zu gleichen Reinhardtsgrimma, da er - wie er meinte Teilen.
Aufgaben zu tun hatte. Er wollte fachlich beeren an und erntete Salat, Rot- und Weiß weiterkommen, beherrschte sogar mehrere kohl, Kohlrabi, Blumenkohl, Tomaten, GurSprachen. Karliczek hatte für die Suche eines ken, Sellerie und Kartoffeln sowie Spätkohl, Nachfolgers bereits eine Anzeige geschaltet Spinat und Winterspinat, Champignons, und suchte bevorzugt nach Schlesiern. ${ }^{17} \quad$ Möhren und Zwiebeln. Außerdem zog er Anfang Mai trat E. Bumke ${ }^{118}$ (1908-?) aus Teppichbeet-Pflanzen, Hortensien, BegoKönigshütte, Provinz Schlesien (heute nien und Schnittchrysanthemen. Diese verChorzów, powiat chorzów, województwo kaufte er als Topfpflanzen und Schnittbluśląskie) seine Gärtnergehilfenstelle in Rein- men. Besonders am Muttertag erzielte er dahardtsgrimma an, wurde jedoch bereits mit gute Einnahmen. Die eingebrachte Ende des Monats wieder entlassen. Dem Ur- Ernte, die nicht in der Schlossküche verarteil Karliczeks zu Folge rauchte er viel und beitet wurde, verkaufte man unter anderem steckte dabei die Frühbeete und sogar sein an Großmarkthändler aus Dresden. Die Geeigenes Bett in Brand. Weiter berichtet Kar- winne gingen natürlich an die Schlossherrliczek an von Schönberg: »Er ist wohl ein schaft. Gegen Ende des Jahres 1929 wurden Heizer, aber kein Gärtner. «119 die Einnahmen, vermutlich mangels Käufern, geringer. Karliczek berichtete von einer Schon im Juni folgte Herbert Sommer, der hohen Arbeitslosigkeit. ${ }^{123}$ Erst im Frühjahr am 27. März 1910 im Bezirk Breslau als Sohn 1930 verzeichnete die Schlossgärtnerei wieeines Försters geboren wurde. Berufserfah- der deutlich steigende Einnahmen. Im Mai rung hatte er bereits in großen Handelsgärt- kündigte Sommer seine Gehilfenstelle, um nereien gesammelt. ${ }^{120}$ Ein guter Gehilfe war sich zu verändern. ${ }^{124} \mathrm{Im}$ Juli folgte ihm $\mathrm{Ar}-$ nötig, denn Gärtner Hinz hatte die Schloss- thur Hirsch (1908-?) als Gärtnergehilfe gärtnerei in einem schlechten Zustand hin- nach. ${ }^{125}$ Das Jahr 1930 war zudem eine Herterlassen. So klagte Karliczek in einem ausforderung für die Obstbäume und damit Schreiben an Maximilian Senfft von Pilsach: für Karliczeks Einnahmen. Der Sommer war sehr trocken, der Herbst brachte frühen "[...] aber in was für einem verrohtesten Frost. Es wurden Ernteeinbußen, verfaultes Zustand ich die Gärtnerei übernahm wird Obst und sogar erfrorene Obstbäume vernicht geschrieben. Ungestrichene Früh- zeichnet. Alle für den Verkauf und die Debeetfenster und Häuschen wie sah das koration des Schlosses vorgesehenen BluGelände aus, und die Obstbäume das men wurden durch den Frost vernichtet. können die Einwohner von R'grimme be- Trotz der guten Einnahmen zu Beginn des stätigen. Meine Bücher beweisen, daß ich Jahres und einer besseren Obsternte als im Einnahmen hatte, das soll mir erst ein Vorjahr musste Karliczek die Arbeiter frühGärtner vormachen, mit einigen Leuten zeitig entlassen. ${ }^{126}$

solch gute Erträge zu erzielen $[\ldots] \ll .{ }^{121}$

Auch das Jahr 1931 sollte sich als schwierig erweisen. Im Frühjahr brach die Maul- und ausging, dass es mindestens zwei Jahre dau- Klauenseuche in Reinhardtsgrimma aus, der ern würde, die Gärtnerei wieder rentabel zu Juni war trocken und von Juli bis Oktober machen. Er riet Karliczek: »Machen sie, was war es kalt und regnerisch. ${ }^{127}$ Die Einnahsie leisten können gut und ordentlich. ${ }^{122}$ men lagen in einem ähnlichen Bereich wie Karliczek wiederum machte sich an die Ar- jene des Vorjahres. Nach nicht einmal vier beit. Er kümmerte sich um die Baumschule Monaten wurde Hirsch seitens der Gutsherund den Obstschnitt. Im Lauf der Jahre ern- rin gekündigt, da er sich weigerte, gröbere tete er von den Obstbäumen Pflaumen, Kir- Arbeiten zu übernehmen und keine Akschen, Äpfel und Birnen, baute Beerenobst kordarbeit leistete. Auch in diesem Fall bewie Erdbeeren, Johannisbeeren und Stachel- sorgte Karliczek in kurzer Zeit Ersatz. Einen 
möglichen Gehilfen ${ }^{128}$ fand er in seiner alten Senfft von Pilsachs dazu entschlossen, die Heimat Schlesien. ${ }^{29}$ Dieser wurde jedoch Gärtnerei zu verpachten, konnte bisher erst einmal nicht eingestellt.

Das Jahr 1932 begann mit Lohnkürzungen für die Landarbeiter. Auch Karliczek erhielt nur noch 103,84 Reichsmark. ${ }^{130}$ Bis April hielt er den Betrieb der Schlossgärtnerei mit Hilfe seiner Frau $^{131}$ und einigen Landarbeitern aufrecht. ${ }^{132}$ Als der am 27. Februar 1913 im oberschlesischen Roswadze, Kreis Oppeln, Provinz Schlesien (heute Rozwadza, powiat krapkowicki, województwo opolskie) geborene Erich Kreutz, Sohn eines oberschlesischen Schlossgärtners am 1. April 1932 eingestellt wurde, lag noch Schnee. ${ }^{133}$ Der Ernteertrag war vermutlich gering. Im Lauf des Jahres klagte Karliczek in seinen brieflichen Berichten an von Schönberg über geringe Einnahmen. Die Verkaufspreise für Gemüse wurden immer niedriger, sodass er im September einige Hilfsarbeiter entlassen musste. Andererseits kritisierte von Schönberg Karliczeks hohe Ausgaben im Vergleich zu den geringen Einnahmen. ${ }^{134}$ Ein Lösungsansatz hierfür wurde auf »politischer Ebene« gesucht. Nach der Auflösung seiner Stahlhelmgruppe trat Karliczek in die »hiesige Partei« (vermutlich NSDAP Ortsgruppe Reinhardtsgrimma) ein. Davon erhoffte er sich mehr Kundschaft, da er beobachtet hatte, dass die Dorfbewohner nur bei Parteimitgliedern kauften. ${ }^{135}$ Nichtsdestotrotz musste Kreutz im November auf Geheiß der Gutsherrin entlassen werden. ${ }^{136}$ Eine erneute Anstellung im Frühjahr 1933 wenn das Geschäft wieder besser laufe, wurde ihm in Aussicht gestellt. ${ }^{137}$ Wahr scheinlich arbeitete er aber nicht noch einmal in Reinhardtsgrimma. Denn auch 1933 blieben die Einnahmen gering. In einigen seiner Briefe wies Karliczek auf die hohe Arbeitslosigkeit im Ort hin. ${ }^{138}$ nicht eindeutig geklärt werden. Die Einnahmen der Schlossgärtnerei waren in den Vorjahren zurückgegangen, demgegenüber boten die fixen Pachteinnahmen den Gutsherren eine gewisse Planungssicherheit. Als vorteilhaft für Karliczek erwiesen sich sicherlich der bereits bestehende Kundenstamm und die vorhandene Infrastruktur. Zudem war er gegenüber den Senfft von Pilsachs nun weniger weisungsgebunden - ein Schritt in die berufliche Selbstständigkeit. Für 600 Reichsmark pro Jahr konnte er nun auf eigene Rechnung Gartenprodukte wie Obst, Gemüse und Blumen aus der Schlossgärtnerei anbieten. Die Obstbäume waren von seiner Pacht ausgeschlossen. Den Schlosspark musste er weiter pflegen, genauso die Bienenstöcke. Ein weiterer Absatz des Pachtvertrages besagte, dass die unentgeltliche Grabpflege auf dem Schlossfriedhof vorzunehmen sei. Am 31. März 1939 endete der Pachtvertrag. Die Übergabe der Schlossgärtnerei wurde durch Schübner vollzogen. In einem Brief an Alpheda Senfft von Pilsach schrieb er:

»Die im Protokoll mit aufgeführten, dem Gärtner G. Karliczek gehörigen Gegenstände und Pflanzen empfehle ich zu übernehmen, die dafür geforderten Preise sind annehmbar. $\ll^{140}$

Trotzdem gab es letztendlich Auseinandersetzungen über die während der Pachtzeit käuflich erworbenen Pflanzen. Diese fanden per Brief statt, denn Karliczek hatte Reinhardtsgrimma 1939 verlassen, vermutlich um eine Gärtnerei in Chemnitz zu übernehmen. ${ }^{141}$ Hierfür forderte er sein Zeugnis ein. In diesem bekundet Generalmajor Senfft von Pilsachs Sohn Ott:

Am 15. Februar 1933 unterschrieb Karliczek einen Pachtvertrag für die Schlossgärtnerei Reinhardtsgrimma auf sechs Jahre, wofür er am 31. März 1933 eine Kaution von 200 Reichsmark hinterlegte. ${ }^{139}$ Warum sich die

»Herr Georg Karliczek ist von 1.X.28 bis zum 31.III 1933 als Gärtner in der Rittergutsgärtnerei zuvor bis August 31 durch meinen Vater, von dann ab durch mich, eingestellt gewesen. Er hat während die- ser Zeit mit Sachkenntnis, zu unserer wanderte Gärtner nach Reinhardtsgrimma vollsten Zufriedenheit die umfangreiche Gärtnerei bewirtschaftet. «142

Mit diesem Zeugnis endet Karliczeks Wirken in Reinhardtsgrimma

Anhand der Ausführungen zu Karliczek wird deutlich, wie sich die Rolle des herrschaftlichen Gutsgärtners in den ersten Jahrzehnten des 20. Jahrhunderts wandelte. Berufsständisch zwar abgesichert, sah er sich mehr und mehr ökonomischen Zwängen ausgesetzt, die vor allem als Folge des Ersten Weltkriegs die ländliche Bevölkerung trafen. Inflation und Weltwirtschaftskrise hinterließen ihre Spuren. Viele der klassischen Gutsgärtnereien wurden aufgelöst oder in eigenständige Betriebe umgewandelt, das heißt verpachtet. Eine systematische Untersuchung hierzu wurde bisher nicht vorgenommen.

Zudem scheinen soziale Konzepte unterschwellig eine Rolle zu spielen: Die standesbewusst agierende Gutsherrin und der eigenständige Gutsgärtner müssen sich am Ende einigen. Zwei Welten stehen sich in ihnen konträr gegenüber. Darüber hinaus ist auch eine Politisierung des privaten Leben spürbar, wenn der Einkauf von Gärtnereiwaren anscheinend nicht mehr nach sachlichen, sondern ideologischen Gründen geschieht.

\section{Resümee}

Die Geschichte der Reinhardtsgrimmaer Gutsgärtner muss aufgrund der lückigen Aktenlage unvollständig bleiben. Durch die eingehende Untersuchung und Darstellung der überkommenen Quellen konnten allerdings recht detaillierte Einsichten in das Leben und Wirken einiger Gutsgärtner gewährt werden. Dabei dürfte ihr facettenreiches Arbeitsspektrum ebenso erkennbar geworden sein wie die Tatsache, dass zumeist sehr versierte, in Gartenbau und Botanik bereien und Gartenanlagen ausgebildet worden waren. Dies ist dabei auch Ausweis der wirtschaftlichen Potenz und Anspruchshaltung der Gutsherrschaft in Reinhardtsgrimma und letztlich auch der Qualitäten des Gutsgartens in seinen jeweiligen Ausprägungen.

Darüber hinaus geben die Ausführungen Einblicke in die sozialen Verhältnisse der jeweiligen Epochen bis hinunter auf die Ebene der Familie und (fehlenden) Privatsphäre so durch den vom Gärtner zu erbringenden Nachweis von "geordneten Verhältnissen « bei Antritt einer Bestallung. Dabei konnten - quasi en passant - auch zeitgenössische Frauenbilder beleuchtet werden, nach denen Frauen teilweise qua Bestallungsurkunde die Rolle als (zumeist unbezahlte) Hilfskraft des Gärtners - neben der Haushaltsführung auch zuständig für den Verkauf von Ernteerzeugnissen, für die Hilfe beim Pikieren oder der Blumenbinderei - zugeteilt wurde. Dabei fand diese Praxis nicht nur in Reinhardtsgrimma Anwendung, sondern entsprach vielmehr den allgemeinen Gepflogenheiten:

"Nicht zu vergessen sind darüber hinaus die Tätigkeits- und Verantwortungsbereiche der Gärtnersfrauen, die mit ihren Männern ein Arbeitspaar bildeten. Zu ihren Aufgaben gehörte u. a. die Versorgung der Vieh- und Milchwirtschaft, die oft mit der Gärtnerstelle verbunden war. Sie waren aber auch mit allen anderen Tätigkeiten im Garten bestens vertraut. $\aleph^{143}$

Durch die Vielzahl der recherchierten und hier aufgezeigten biografischen Bezüge hoffen die Autorinnen, Anknüpfungspunkte für die Erforschung weiterer historischer Gärten und - ganz im Sinne dieser Arbeit weiterer Gärtnerbiografien bieten zu können. geholt wurden, die in namhaften Gärtne- 
Aus dem Brief des Gärtners Paul Raser an seinen Dienstherren, den Generalmajor Senfft von Pilsach, verfasst in Kutschlau bei Schwiebus am 21.11.1927 (SächsHStA, 10505, Nr. 329, Gärtner Hinz betreffend 1927-1928).

In den Bestallungsurkunden und Dienstverträgen der Gärtner von Reinhardtsgrimma findet sich zum Teil auch die Bezeichnung "Schlossgärtner" - die Berufsbezeichnungen wurden somit seitens der Gutsherren nicht immer einheitlich verwendet.

SächsHStA, 10505, Nr. 179, Anstellungsvertrag für den Gärtner Johann Friedrich Reuter 1809.

4 Ebd., Nr. 423, Gutsverwaltung in Reinhardtsgrimma 1907 bis 1913 und Ebd., Nr. 121, Gartnerei- und Pilsach als Kunstgärtner bezeichnet und empfing einen Jahreslohn von 1100 Reichsmark Ansping ist lediglich überliefert, dass er 1913 einen nsten Küchen- und Stubenofen erhielt und am 16.08 . Kuch eine Rechnt rei Gebhardt und Comp. entgegennahm. Er hatte dort 100 Primula chinensis, 100 Primula obconica hybrid grandiflora, 200 Cinerarien max. nana, 200

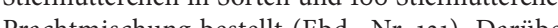
Prachtrischung bestellt (Ebd., Nr. 121). Darübe hinaus wird in den Gartnerei-Kontobuchern von 1908-1912 fortlaufend eine Frau Ettrich genannt, die Lohn für ihre Tätigkeiten in der Schlossgärtnere bezog, was vermuten lässt, dass es sich hier um die Ehefrau des Kunstgärtners handelt (Ebd., Nr. 27, Kontobuch der Schlossgärtnerei 1908-1912).

Wilhelm Dobbrunz war ab dem 01.10.1917 in Rein hardtsgrimma bei den Senfft von Pilsachs angestellt. Biografische Aussagen zu Dobbrunz können anhand der dünnen Aktenlage nicht getroffen werden. Es ist lediglich der Hinweis auf ein Magenleiden überliefert: »Herr Gärtner Dobbrunz ist magenleidend und bedarf einer reizlosen Kost: zweckmäßig sind besonders Milch und Milchspeisen.« Dr. Künzel 08.09.1922 (SächsHStA, 10505, Nr. 285, Gärtner Wilhelm Dobbrunz 1922-1923). Sein gärtnerisches Wirken in Reinhardtsgrimma ist - bis auf wenige Rechnungen, die an ihn gerichtet sind nicht dokumentiert. Sein Anstellungsvertrag is zwar überkommen, liefert aber keine Informationen, die den hier nen, die den wïr hinzufugen würden. Ab August 1923 verlieren sich die Spuren seines Wirkens, sodass angenommen werden kann, dass er in ebenjenem Jahr das

verließ. Die Grande hierfur sind nicht bekannt.

SachsHStA, 10505, Nr. 330, Personalangelegenheiten des Gartners Paul Raser in Reinhardtsgrimma 1927. Ebd., Nr. 329, Anstellung und Tatigkeit des Gärtners Joseph Hinz in Reinhardtsgrimma 1927-1928 un ebd., Nr. 266, Schlossgärtner Joseph Hinz in Reinhardtsgrimma 1926-1928.

8 Ebd., Nr. 127, Schlossgärtnerei Reinhardtsgrimma 1928-1933.

Ebd., Nr. 264, Forst- und Gärtnereiangelegenheite von Reinhardtsgrimma 1909, 1911-1940. Die Mutte der Gärtnerin war Margarethe von Koppenfels
(1874-1956), geborene Martens. Diese lebte ab 1920 in der Villa ihres Bruders, dem Schriftsteller Dr. phil. Kurt Martens (1870-1945), auf dem Erckelschen Weinberg in Dresden - so vermutlich anfäng lich auch ihre Tochter Christa. Nachdem bei dem Bombenangriff am 13./14. Februar 1945 die Villa niedergebrannt war, soll Frau von Koppenfels zu ihrer Tochter nach Reinhardtsgrimma geflohen sein, um da Asyl zu erhalten (Vgl. Stadtwiki Dresden, Eintrag zu Margarethe von Koppenfels, abruf(2) garen_. Sächor

Dieses umfasst Bestallungsurkunden, Gärtnerei wechsel

SächsHStA, 10505, Nr. 36, Grundbuch 1865-1888 "Geschichte des Rittergutes Ober- und NiederReinhardtsgrimma beginnend mit dem Jahr $1865 \%$

Ebd., Nr. 35, Flurbuch 1875

Die im März 2020 erschiene Publikation Michael Seilers, "Landschaftsgarten Pfaueninsel. Geschichte seiner Gestaltung und Erhaltung «, behandelt im 5 . Kapitel den ehemaligen Hofgärtner Adolf Reuter (1869-1901). Dazu, ob er ein Verwandter Johann Friedrich Reuters gewesen sein könnte, lassen Seilers Ausführungen allerdings keine Aussage zu.

SächsHStA, 10505, Nr. 179, Anstellungsvertrag fü den Gärtner Johann Friedrich Reuter 1809.

6 N.N.: Das Königreich Sachsen in allen seinen Beziehungen oder übersichtliche Darstellung seine Geschichte, Geographie, Staatsverfassung Staatsverwaltung und Staatskräfte, der Civil- und Militairbehörden mit ihren Titulaturen, der Unterrichts-, Gewerbs-, Gesundheits- und Heilanstalten, milden Stiftungen usw. nebst Anleitung zur Fertigung schriftlicher Aufsätze und dergl., Ein Handbuch für alle Stände, Leipzig 1840

Fahnert, Paul: Herrschaft und Gesinde. Eine Darstellung des im Königreiche Sachsen geltenden Gesinderechts nach der Revidirten Gesindeordnung vom 2. Mai 1882 mit Gesetzesabdruck, in Meinholds Juristische Handbibliothek, Dresden (66) 1896.

Wie der Kutscher oder die Stubenmagd gehörte er also den Dienstboten an. Im Vergleich dazu gehören Maagde, Knechte, der Schirrmeister oder Ochsen- und Pferdejungen zum landwirtschaftlichen Gesinde.

SächsHStA, 10505, Nr. 251, Kostenvoranschlag für noch fertig zu bauende Gebäude 1811 . 2 Ebd.

Volkamer, Johann Christoph: Continuation de Nürnbergischen Hesperidum, Nürnberg 1714, S.

2 Beauman, Francesca: The Pineapple. King of Fruits, 2. Aufl., London 2011, S. 151.

23 Ebd., S. 72.

4 Köhler, Marcus: Schwöbber und die Welt, in: Bücherei des Deutschen Gartenbaues e.V. (Hg.) Geschichte der Gartenkultur. Von Blumisten, Kunstgärtnern, Mistbeeten und Pomologien. 1.
Aufl., Berlin 2015, S. 55 und Volkamer 1714, S. 22-23. 25 Schillig, Christiane: Schloss Schwöbber - Ein Neubeginn. Wo die Familie Münchhausen lebte, in: Monumente Oktober/2014, online abrufbar unter: https://www.monumente-online.de/de/ausgaben/2014/5/schloss-schwoebber-ein-neubeginn. php (Zugriff am: 10.11.2020)

26 Wimmer, Clemens Alexander: Hof- und Gutsgärtner, in: Bücherei des Deutschen Gartenbaues e.V. (Hg.): Geschichte der Gartenkultur. Von Blumisten, Kunstgärtnern, Mistbeeten und Pomologien, Aufl., Berlin 2015, S. 22-24.

27 Ricker, Julia: Erdbeeren im März. Die Wiedergeburt historischer Küchengärten, in: Monumente Oktober/2013, online abrufbar unter: https://www.monumente-online.de/de/ausgaben.backup/2013/5/erdbeeren-im-maerz.php\#.Xq3ikc3grGg (Zugriff am: 10.11.2020).

28 SächsHStA, 10505, Nr. 179, Anstellungsvertrag für den Gärtner Reuter 1809

29 Ebd.

30 Ebd.

31 Der heutzutage hierfür verwendete Begriff lautet "Okulation « und meint eine Art der Pflanzenveredelung, bei der eine ruhende Knospe des Edelreises unter die Rinde der Unterlage gesetzt wird.

32 SächsHStA, 10505, Nr. 179, Anstellungsvertrag fü den Gärtner Reuter 1809 .

33 Wimmer, Clemens Alexander: Zwischen Hofhandwerk und Zunft. Zur sozialen Stellung der Hofgärtner, in: Generaldirektion der Stiftung Preußisch Schlösser und Gärten Berlin-Brandenburg (Hg.): Preußisch Grün. Hofgärtner in Brandenburg-PreuBen, Berlin 2004, S. 120-133.

34 SächsHStAD, 10505, Nr. 179, Anstellungsvertrag für den Gärtner Reuter 1809

35 Wimmer 2004a, S. 130

36 Teichert, Oscar: Geschichte der Ziergärten und der Ziergärtnerei in Deutschland während der Herrschaft des regelmässigen Gartenstyls, Berlin 1865, S. $48-49$.

37 Wimmer, Clemens Alexander: Die Tätigkeiten der Hofgärtner in: Generaldirektion der Stiftung PreuBische Schlösser und Gärten Berlin-Brandenburg (H.): Preußisch Grin. Hof burg-Preußen, Berlin 2004, S. 174-186.

38 Fahnert 1896, S. 48-49.

istian Friedrich; Gericke, Friedrich Karl Gustav (Hg.): Die Hausmutter in allen ihren Geschäften, Leipzig 1778, S. 32.

40 SächsHStA, 10505, Nr. 179, Anstellungsvertrag für den Gärtner Johann Friedrich Reuter 1809

41 Die fünfbändige Enzyklopädie richtete sich an ade-

lige und gebildete Hausfrauen und enthielt Anleitungen zur Haushaltsführung (neben Ratschlägen zum Kochen und Backen u.a. auch zur Kindererziehung und zur Führung des Gesindes).

42 Germershausen/Gericke 1778, S. 33.

43 Wimmer, Clemens Alexander: Die Ausbildung de Hofgärtner, in: Bücherei des Deutschen Gartenbaues e.V. (Hg.): Geschichte der Gartenkultur. Von
Blumisten, Kunstgärtnern, Mistbeeten und Pomologien. 1. Aufl., Berlin 2015, S. 135-163.

Ein Hinweis fuhrte nach Thüringen. In Rudolstad ersuchte am 08.02.1795 ein Johann Friedrich Reute aus Arolsen um Anstellung bei dem Fursten von Schwarzburg-Rudolstadt. Leider handelte es sich hierbei um einen Koch und keinen Gärtner (Akte Rudolstädter Schlossarchiv Nr. 784).

SächsHStA, 10505, Nr. 330, Personalangelegenheiten des Gärtners Paul Raser in Reinhardtsgrimma 1927. 46 Ebd. - Zeugnisabschriften.

47 Ebd.

Mularczyk, Magdalena: Der Botanische Garten der Universität Wrocław - Geschichte und Gegenwart, in: Botanischer Garten und Botanisches Museun (Hg.): Englera, Nr. 30, Berlin 2013, S. 101-112.

99 SächsHStA, 10505, Nr. 330, Personalangelegenheiten des Gärtners Paul Raser in Reinhardtsgrimma 1927 - Zeugnisabschriften.

50 Ebd., Nr.330, Den Gärtner Paul Raser betreffend 1927.

d., Rasers Arbeitszeugnis verfasst von Oberst Senfft von Pilsach am 09.02.1927.

53 Ebd., Nr. 452, Gärtnereirechnungen 1926-1927.

Ebd., Rechnung an Hr. Rittergutsbesitzer v. Senfft, 15.12.1926.

Ebd., Nr. 330, Den Gärtner Paul Raser betreffen 1927, Rasers Arbeitszeugnis verfasst von Obers Senfft von Pilsach am 09.02.1927.

57 Ebd., Den Gartner Paul Raser betreffend 192\%

Ebd., Antwortschreiben Senfft von Pilsachs an Lesser vom 13.11.1927.

De Famille Laux waren die letzten Besitzer des Rittergutes mit klassizistischem Herrenhaus, landschaftlichem Park und Orangerie vor der Enteignung im Zuge der Bodenreform 1945

60 SächsHStA, 10505, Nr. 472, Angelegenheiten des Rittergutes Reinhardtsgrimma 1877-1922, 1934 1945, Schreiben Ernst Laux' an den Generalmajo Senfft von Pilsach vom 14.11.1927.

61 Ebd., Nr. 329 Gärtner Hinz betreffend, 1927-1928, Rasers Brief an Senfft von Pilsach, verfasst in Kutschlau bei Schwiebus am 21.11.1927. Die Interpunktion wurde zugunsten des besseren Textverständnisses nachträglich eingefügt.

62 Ebd., Brief Senfft von Pilsachs an Raser vom 26.11.1927.

63 Ebd., Nr. 329, Anstellung und Tätigkeit des Gärtner Joseph Hinz in Reinhardtsgrimma 1927-1928, Zeug nis von Senfft von Pilsach für Hinz ausgestellt vom 01.11.1928.

64 Ebd., Arbeitsvertrag von Hinz vom 17.08.1927.

$\mathrm{Zu}$ dieser Entwicklung vermerken Gert Gröning und Joachim Wolschke-Bulmahn: »1918 wurde de erste demokratisch verfaßte Staat in Deutschland, die Weimarer Republik, gegründet. Bis dahin waren neben den kommunalen Gartenämtern und de privaten Auftraggebern aus dem aufsteigenden Bürgertum vor allem die Schloß- und Hofgärtnereien 
adliger Besitzer Dreh- und Angelpunkte professionellen Geschehens auf dem Gebiet der Gartenkul81 Ebd.

Joachim: Grüne Biografien. Biographisches Handbuch zur Landschaftsarchitektur des 20. Jahrhunderts in Deutschland, Berlin/Hannover 1997, S. 5.

66 Die genannte Lehranstalt für Gartenbau, Obstkutur und Pomologie in Reutlingen wurde 1860 von dem Pomologen Eduard Lucas (1816-1882) gegründet. Lucas bearbeitete die Neuauflagen des populären Werks »Christs Gartenbuch für Bürger und Landmann: eine gemeinfaßliche Anleitung zur Anlage und Behandlung des Hausgartens in Beziehung auf Gemüsezucht, Obstbau, Weincultur und Blumenzucht« des berühmten Pomologen Johan Ludwig Christ (1739-1813). Nach Eduard Lucas` Tod übernahm dessen Sohn Friedrich Lucas (1842-?) die ubernahm dessen Sohn Friedrich Lucas (1842-?) die Leitung der Lehranstalt und verlegte nun Christ's Gartenbuch unter dem Titel »Christ-Lucas Gartenbuch. Eine gemeinfaßliche Anleitung zur Anlage und Behandlung des Hausgartens und zur Kultur der Blumen, Gemuse, Obstbaume und Reben Demnach handelte es sich bei Christ und Lucas un ZächsHStA, 10505, Nr. 329, Anstellung und Tätigkeit 67 SächsHStA, 10505, Nr. 329, Anstellung und Tätigkeit
des Gärtners Joseph Hinz in Reinhardtsgrimma des Gartners Joseph Hinz in Reinhardtsgrimma 1927-1928, Bewerbungsanschreiben

Senfft von Pilsach vom 08.02.1927.

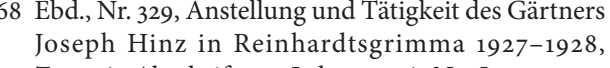
Zeugnis-Abschriften - Lehrzeugnis No. I.

69 Ebd., Zeugnis-Abschriften - No. II.

70 Ebd., Zeugnis-Abschriften - No. III

71 Landesdenkmalamt Berlin; Haspel, Jörg; von Krosigk, Klaus (Hg.): Gartendenkmale in Berlin. Privatgärten, Petersberg 2009, S. 151. LK 16678 B423-21 Bibo GLA

72 SächsHStA, 10505, Nr. 329, Anstellung und Tätigkeit des Gärtners Joseph Hinz in Reinhardtsgrimma 1927-1928, Zeugnis-Abschriften - No. IV.

73 Ebd., Zeugnis-Abschriften - No. V.

74 Ebd., Nr. 329, Anstellung und Tätigkeit des Gärtners Joseph Hinz in Reinhardtsgrimma 1927-1928, Zeugnis-Abschriften $\mathrm{No}$ VI

75 Köhler, Marcus; Haase, Christoph (Hg.): Die Gärte Peter Joseph Lennés im heutigen Polen. Eine Spurensuche jenseits von Oder und Neisse, Edition GartenReich-Bd. 2, Wettin-Löbejün 2016, S. 146147.

76 SächsHStA, 10505, Nr. 329, Anstellung und Tätigkeit des Gärtners Joseph Hinz in Reinhardtsgrimma 1927-1928, Schreiben vom 16.02.1927.

77 Ebd., Schreiben vom 21.02.1927.

8 Oberst Senfft von Pilsach, der 1931 verstarb, litt z dieser Zeit wohl zunehmend an einem Nervenleiden und saß zudem im Rollstuhl.

79 SächsHStA, 10505, Nr. 329, Anstellung und Tätigkeit des Gärtners Joseph Hinz in Reinhardtsgrimm 1927-1928, Schreiben von Alpheda Senfft von Pilsach an Hinz datiert auf Mitte Mai 1928.

80 Ebd., Nr. 127, Schlossgärtnerei Reinhardtsgrimma
1928-1933.

2 Ebd., Schreiben von Hinz an Senfft von Pilsach vom 01.09.1928.

Ebd., Nr. 127, Schlossgärtnerei Reinhardtsgrimma 1928-1933.

Ebd., Nr. 380, Die Entlassung des Obergärtners Joseph Hinz in Reinhardtsgrimma 1928.

Ebd., Nr. 127, Schlossgärtnerei Reinhardtsgrimma 1928-1933.

86 Ebd., Nr. 329, Anstellung und Tätigkeit des Gärtners Joseph Hinz in Reinhardtsgrimma 1927-1928, Hinz Arbeitszeugnis ausgestellt von Oberst Senfft von Pilsach.

77 Ebd., Nr. 264, Forst- und Gärtnereiangelegenheiten von Reinhardtsgrimma ohne Jahr.

Ebd, $\mathrm{Nr}_{127}$, Schlossgärtnerei Reinhardtsgrimm 1928-1933. In welcher Gärtnerzeitung voon Schën1928 bersechen in his(stark nachgefrag 9 Ebd.

Ebd., Nr. 272, Anstellungs- und Tariffragen des Gärtners Karliczek 1928

Dehio, Georg: Handbuch der deutschen Kunstdenkmäler, Brandenburg, bearb. von Gerhard Vinken, Berlin 2000, S. 1089

Wolf, Katharina; Taufmann, Anne-Christin; Sanft, Henriette: Gerswalde. Schlossgärtnerei an der alten Wasserburg, Parkpflegewerk-Gerswalde, Betreuer Prof. Dr. Marcus Köhler. Hochschule Neubrandenburg University of applied Sciences, Landschaftsarchitektur und Umweltplanung, Projekt Gerswalde, Neubrandenburg 2006, S. 23 u. 68, unveröffentlicht. 93 SächsHStA, 10505, Nr. 127, Schlossgärtnerei Reinhardtsgrimma $1928-1933$.

94 Ebd.

96 SächsHStA, 10505, Nr. 127, Schlossgärtnerei Reinhardtsgrimma 1928-1933.

97 Wolf; Taufmann; Sanft 2006, S. 24

98 SächsHStA, 10505, Nr. 127, Schlossgärtnerei Reinhardtsgrimma 1928-1933. Der »Stahlhelm« war eine Ordsenistion, in der ehemalige Kriegstein Anerkention Anerken lik und politschen System der Weimarer Repub-

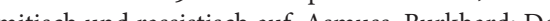
mitsch uns Stahlher, Bund der Frontsoldaten, Lebendige Museum Online, 2014, in. h/ps.//Www.dhm.de/ lemo/kapitel/weimarer-republik/innenpolitik/ stahlhelm/, Stand: 29.10.2020.

Kitzing, Andreas: Das Leben eines märkischen Junkers. Hans Wichard von Rochow-Stülpe (18981945), Wahlsdorf 1998

Der Vorname von Schleutz konnte trotz intensive Recherchen nicht in Erfahrung gebracht werden. Badstübner-Gröger, Sibylle: Schlösser und Gärten der Mark, Stülpe, in: Badstübner-Gröger, Sibylle (Hg.) Band 109, Berlin 2010, S. 6.
102 Brandenburgisches Landesamt für Denkmalpflege und Archäologisches Landesmuseum: Gutspark Gerswalde, Dokumentnr.: 09131385. BadstübnerGröger 2010, S. 8.

03 SächsHStA, 10505, Nr. 127, Schlossgärtnerei Reinhardtsgrimma 1928-1933.

104Ebd., Schreiben von Schönberg an Senfft von Pilsach vom 24.07.1928.

105 Ebd., Nr. 127, Schlossgärtnerei Reinhardtsgrimma 1928-1933.

106Im »Tarifvertrag zwischen der sozialen Abteilung des Sächsischen Landbundes und dem Deutschen Gartenverband « in der Fassung von 1925 steht in $\$$ 13: »Etwa zu stellende Kaution ist mündelsicher anzulegen. Die Kautionssumme ist angemessen zu verzinsen und darf nur als Sicherheit für die Einhaltung dieses Vertrages und zur Deckung vo tunsprüchen nach den Bestimmuneckung vo dienen.« (SächsHStA, 10505, Nr. 272, Anstellungsund Tariffragen des Gärtners Karliczek 1928).

107 SächsHStA, 10505, Nr. 127, Schlossgärtnerei Rein hardtsgrimma 1928-1933.

08Ebd., undatiertes Schreiben von Schönbergs an Senfft von Pilsach.

109 Ebd., Nr. 127, Schlossgärtnerei Reinhardtsgrimm 1928-1933, Brief von Schönbergs an Karliczek vom 28.08.1928.

10 Ebd., Nr. 380, Entlassung des Obergärtners Joseph Hinz in Reinhardtsgrimma 1928, Inventar vom O2.10.1928.

11 Über die Hintergründe der früher als von der Gutsherrschaft in Aussicht gestellt vollzogenen Hochzeit liegen keine Informationen vor

112 SächsHStA, 10505, Nr. 127, Schlossgärtnerei Reinhardtsgrimma 1928-1933.

113 Ebd., Nr. 264, Forst- und Gärtnereiangelegenheiten von Reinhardtsgrimma 1909, 1911-1940 - GärtnerDeputat vom 26.11.1928.

114 Ebd.

$115 \$ 16$ der Landarbeitsordnung von 1919: »Wichtiger Grund zur sofortigen Lösung des Vertrags ist jeder Umstand, mit Rücksicht auf den die Fortsetzung des Dienstvertrags einer Vertragspartei nicht mehr zugemutet werden kann. Solche Gründe sind insbesondere Tätlichkeiten, grobe Beleidigungen, unsittliche Zumutungen im Arbeitsverhältnisse, beharrliche Verweigerung oder grobe Vernachlässigung der Dienstleistungen, wiederholt unpünktliche Lohnzahlung, anhaltend schlechte Kost und gesundheitsschädliche Wohnung. Politische und gewerkschaftliche Betätigung ist kein Entlassungsgrund.«, in: liche Betatigung ist kein Entlassungsgrund.", in:
Reichsregierung: Reichsgesetzblatt Nr. 21, VorläuReichsregierung: Reichsgesetzblatt
fige Landarbeitsordnung, Berlin 1919. fige Landarbeitsordnung, Berlin 1919.
6 SächsHStA, 10505, Nr. 272, Anstellungs- und Tarif-

fragen von Gärtner Karliczek 1928.

117 Ebd., Nr. 127, Schlossgärtnerei Reinhardtsgrimm 1928-1933, Schreiben von Karliczek an von Schönberg vom 24.02.1929.

Der Vorname von Bumke konnte trotz intensiver Recherchen nicht aufgelöst werden.

19 SächsHStA, 10505, Schreiben von Karliczek an vo
Schönberg vom 26.05.1929.

Ebd., Schreiben von Karliczek an von Schönberg vom 09.06 .1929 .

21 Ebd., Nr. 264, Forst- und Gärtnereiangelegenheiten von Reinhardtsgrimma1909, 1911-1940, Schreiben von Karliczek an Senfft von Pilsach vom 22.02.1940.

Ebd., Nr. 127, Schlossgärtnerei Reinhardtsgrimma 1928-1933, Schreiben von Schönbergs an Karliczek vom 07.06.1929.

23 Ebd., Schreiben von Karliczek an von Schönberg vom 08.12.1929.

vom 04.05.1930.

125 Ebd., Nr. 264, Forst- und Gärtnereiangelegenheiten 1909, 1911-1940, Anstellungsvertrag für Gärtnergehilfen Arthur Hirsch vom 15.06.1930.

26 Ebd., Nr. 127, Schlossgärtnerei Reinhardtsgrimma 1928-1933, Schreiben von Karliczek an von Schönberg vom 06.07.1930

27 Ebd., Schreiben von Karliczek an von Schönberg vom 08.03.1931.

Name und die Lebensdaten des Gärtnergehilfen werden in den Quellen nicht genannt.

2 SächsHStA, 10505, Nr. 127,Schreiben von Karliczek an von Schönberg vom 04.11.1931.

Ebd., Schlossgärtnerei Reinhardtsgrimma 1928 1933.

Diese half u. a. mit beim Verkauf und Pikieren (Ebd.).

32 Ebd., Schreiben von Karliczek an von Schönberg vom 06.03.1932.

Ebd., Schreiben von Karliczek an von Schönber vom 10.04.1932.

Ebd., Schreiben von Schönbergs an Karliczek vom 24.11.1932.

Ebd., Schreiben von Karliczek an von Schönberg vom 03.11.1932.

136 Ebd., Schreiben von Schönbergs an Karliczek vom 24.11.1932.

Ebd., Schreiben von Karliczek an von Schönber vom 08.05.1932.

38 Ebd., Schreiben von Karliczek an von Schönberg vom 08.12.1929 und vom 10.01.1933.

39 Ebd., Nr. 264, Forst- und Gärtnereiangelegenheiten von Reinhardtsgrimma 1909, 1911-1940, Pachtvertrag vom 15.02.1933.

0 Ebd., Nr. 272, Anstellungs- und Tariffragen von Gärtner Karliczek 1928 41 Ebd.

12 Ebd., Nr. 264, Forst- und Gärtnereiangelegenheiten von Reinhardtsgrimma 1909, 1911-1940, Zeugnis für Georg Karliczek verfasst am 12.05.1939 von Senff von Pilsach

43 Ebert, Jochen: Zwischen Ästhetik und Ökonomie Finanzielle Kosten und wirtschaftlicher Nutzen von fürstlichen, adeligen und bürgerlichen Gartenanlagen, in: Schweizer, Stefan; Winter, Sascha (Hg.) Gartenkunst in Deutschland. Von der Frühen Neuzeit bis zur Gegenwart. Geschichte- Themen - Perspektiven, Regensburg 2012, S. 187 